\title{
High Flux Isotope Reactor Technical Specifications
}

\section{OAK RIDGE NATIONAL LABORATORY}




\section{DISCLAIMER}

This report was prepared as an account of work sponsored by an agency of the United States Government. Neither the United States Government nor any agency Thereof, nor any of their employees, makes any warranty, express or implied, or assumes any legal liability or responsibility for the accuracy, completeness, or usefulness of any information, apparatus, product, or process disclosed, or represents that its use would not infringe privately owned rights. Reference herein to any specific commercial product, process, or service by trade name, trademark, manufacturer, or otherwise does not necessarily constitute or imply its endorsement, recommendation, or favoring by the United States Government or any agency thereof. The views and opinions of authors expressed herein do not necessarily state or reflect those of the United States Government or any agency thereof. 


\section{DISCLAIMER}

Portions of this document may be illegible in electronic image products. Images are produced from the best available original document. 


\section{Printed in the United States of America. Available trom National Technical Information Service}

U.S. Department of Commerce

5285 Port Royal Road, Springfield, Virginia 22161

Price: Printed Copy $\$ 5.00 ;$ Microfiche $\$ 3.00$

This report was prepared as an account of work sponsored by the United States Government. Neither the United States nor the Energy Research and Development Administration/United States Nuclear Regulatory Commission, nor any of their employees, nor any of their contractors, subcontractors, or their employees, makes any warranty, express or implied, or assumes any legal liability or responsibility for the accuracy, completeness or usefulness of any information, apparatus, product or process disclosed, or represents that its use would not infringe privately owned rights. 
Contract No. W-7405-eng-26

Operations Division

HIGH FLUX ISOTOPE REACTOR

TECHNICAL SPECIFICATIONS

Operations Division Staff

Date Published - March 1977

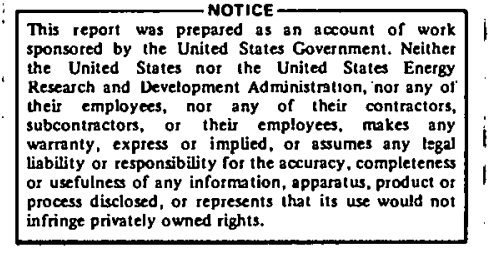

NOTICE This document contains information of a preliminary nature. $I_{t}$ is subject to revision or correction and therefore does not represent a final report.

\author{
OAK RIDGE NATIONAL LABORATORY \\ Uak Kidge, Tennessee 37830 \\ operated by \\ UNION CARBIDE CORPORATION \\ for the \\ ENERGY RESEARCH AND DEVELOPMENT ADMINTSTRATION
}




\section{THIS PAGE}

\section{WAS INTENTIONALLY \\ LEFT BLANK}




\section{CONTENTS}

Page

1. DEfINITIONS . . . . . . . . . . . . . . . . . 1-1

2. SAFETY LIMITS AND LIMITING SAFETY SYSTEM SETTINGS . . . . . 2-1

2.1 Safety Limits . . . . . . . . . . . . . . 2-1

2.1.1 Reactor Power and Reactor Coolant Flow, Coolant

Temperature and Pressure .......... . 2-1

2.2 Limiting Safety System Settings (LSSS) . . . . . . . 2-3

2.2.1 Reactor Power and Reactor Coolant Flow, Coolant

Temperature and Pressure . . . . . . . . 2-3

2.2.2 Failed-Fuel-Element Detector . . . . . . . 2-5

3. LIMITING CONDITIONS FOR OPERATION . . . . . . . . . 3-1

3.1 System Reactivity . . . . . . . . . . . . . 3-1

3.2 Control System . . . . . . . . . . . . 3-5

3. 3 Shim-Safety Plates ............... 3-7

3.4 Reactor Control and Safety Systems . . . . . . . 3-8

3.5 Special Building Hot Exhaust (SBHE) Filter Efficiency . . 3-14

3.6 Containment . . . . . . . . . . . . 3-15

3.7 Primary Coolant System . . . . . . . . . . . 3-17

3.8 Limitations on Experiments . . . . . . . . . 3-19

3.9 Emergency Core Cooling .............. 3-23

3.10 Emergency Shutdown System . . . . . . . . . . 3-24

3.11 Water Height Above Core . . . . . . . . . . . 3-27

3.12 Installation of Target or Its Equivalent in the Flux Trap 3-28

3.13 Radiation Monitoring Equipment . . . . . . . . 3-29

3.14 Core Components . . . . . . . . . . . . 3-30

3.15 Emergency Power . . . . . . . . . . . . . 3-31

4. SURVEILlANCE REQUIREMENTS .. . . . . . . . . . . . . 4-1

4.1 System Reactivity . . . . . . . . . . . . . 4-1

4.2 Control system . . . . . . . . . . . . . 4-2

4.3 Shim-Safety Plates .............. 4-3

4.4 Reactor Control and Safety Systems . . . . . . . . 4-4

4.5 SBHE Filter Efficiency . . . . . . . . . . . 4-6

4.6 Containment ................ . . . . . . 
Page

4.7 Primary Coolant System . . . . . . . . . . 4-8

4.8 Limitations on Experiments . . . . . . . . . . 4-9

4.9 Emergency Core Cooling .............. 4-10

4.10 Emergency Shutdown System . . . . . . . . . . 4-11

4.11 Water Height Above Core . . . . . . . . . . 4-12

4.12 Installation of Target or Its Equivalent in the Flux Trap 4-13

4.13 Radiation Monitoring Equipment . . . . . . . . 4-14

4.14 Core Components . . . . . . . . . . . . . 4-15

4.15 Emorgensy Power.................... . . 4-16

5. DESIGN FEATURES . . . . . . . . . . . . . . 5-1

5.1. Reactor Fuel ................. 5-1

5.2 Reactor Bay .. . . . . . . . . . . . 5-2

5.3 Fuel Storage ............... 5-3

6. ADMINISTRATIVE CONTROLS . . . . . . . . . . . 6-1

6.1 Organlzation . . . . . . . . . . . . . 6-1

6.2 Personnel Qualification . . . . . . . . . . . 6-3

6.3 Staff Requirements . . . . . . . . . . . 6-4

6.4 Facility Modifications . . . . . . . . . . 6-5

6.5 Operating Procedures ............. 6-6

6.6 Action to Be Taken in the Event A Safety Limit. Is

Exceeded ...................,6-7

6.7 Action to Be Taken in the Event of An Abnormal Occurrence 6-8

6.8 Reporting Requirements . . . . . . . . . . . 6-9

6.9 Actions to Be Taken in Regard to Potential Degradations of A Reactor Shutdown System . . . . . . . . . 6-10

6.10 Operating Records . . . . . . . . . . . . . 6-12

6.11 Review Commttees ................. . 6-13

6.11 .1 Reactor Operations Review Committee . . . . . . 6-13

6.11.2 Reactor Experiment Review Commlttee . . . . . . 6-14

6.11.3 Criticality Committee . . . . . . . . . 6-15

6.12 Monitoring of Airborne Effluents . . . . . . . . 6-16

6.13 Control Rod Replacement with New Control Rods . . . . . 6-17

7. REFERENCES . . . . . . . . . . . . . . . . 7-1

APPENDIX - ACCIDENTS AND ANTICIPATED TRANSIENTS . . . . . . . A-1 
TABLES

Page

2.1. Safety Limits on Process Varlables . . . . . . . . . . 2-i

2.2. Limiting Safety System Settings for Process Variables . . . 2-3

3.1. Cases for which Reactor Must Be Subcritical . . . . . . . 3-1

3.2. Minimum Reactor Instrumentation Required for Startup . . . 3-9

3.3. Minimum Reactor Instrumentation Required for Operation . . 3-10 
FIGURES

\section{Page}

3.1. Case IV Subcriticality Check ............. 3-3

6.1. Organizational Chart ................. 6-2 


\section{DEFINITIONS}

The following frequently used terms are defined to aid in the uniform interpretation of these specifications.

1.1 Abnormal Occurrence - An abnormal occurrence is any of the following:

a. Operating in violation of a limiting condition for operation.

b. A release of radioactive materials of a magnitude to indicate a failure of a principal physical boundary.

c. An uncontrolled or unexplained change in reactivity.

d. An observed inadequacy in the implementation of either administrative or procedural controls such that the inadequacy could have caused the existence or development of an unsafe condition in connection with the operation of the reactor.

1.2 Accident - Those transients and excursions which are not expected to occur during the life of the reactor but which have been analyzed in the safety documents.

1.3 Anticipated Transient - Any transient or excursion which could reasonably be expected to occur at least once during the life of the reactor.

1.4 Channel Calibration - A channel calibration is an adjustment of the channel such that its output responds, with acceptable range and accuracy, to known values of the parameter.wich the channel measures or to known input signals when access to the primary element is limited.

1.5 Channel Check - A channel check is a qualitative verification of acceptable performance by observation of channel behavior. This verification shall include comparison of the channel with expected values or other independent channels or methods of measuring the same variable.

1.6. Channel Test - A channel test is the introduction of an appropriate signal into a channel. to verify that it is operable. 
1.7 Control Elements - The set consisting of:

a. Four shim-safety plates which provide reactivity control by varying their positions and by fast insert capability when actuated by the reactor safety system; and

b. The shim-regulating cylinder which provides reactivity control by varying its position and provides automatic power level regulation under direction of the reactor control system.

1.8 Degradation of the Reactor Shutdown System

a. Class 1 - 'l'he actual fallure of the reactor shutdown system to Initiate the protective action when the reactor varlable has exceeded the limiting safety system setting (LSSS) or the premature termination of the protective action. For example: Reactor coolant flow rate decreases to below the LSSS without an automatic trip; the relatching of neutron-absorbing rods prior to achieving the required shutdown margin.

b. Class 2 - Failure or malfunction of components, personnel error, or procedural inadequacy which, due to its affect on multiple units would, by 1 tself, prevent the reactor shutdown system from providing the protective action at the LSSS. For example: In a two-out-of-three system, the drift of the setpoints of two flow channels to values beyond the LSSS; an improper calibracion prucedure which resulted in several setpoint adjustments being effectively beyond the LSSS.

c. Class 3 - Fallure or malfunction of one or more components, personnel error, or procedural inadequacy which reduces the capability of the reactor shutdown system to the extent that the occurrence of a random single failure would prevent the protective action at the LSSS. For example: In a two-out-of-three system, the drift of a single channel setpolnt to a value beyond the LSSS.

d. Class 4 - Failure or malfunction of one or more components, personnel error, or procedural inadequacy affecting a limited number of units such that, although the degree of redundancy may be reduced, the reactor shutdown system retains, even after the application of the single failure criterion, the ability to 
provide the protective action when required (conditions and LSSS) by the technical specifications. For example: In a two-out-offour system, one under-voltage relay falled to perform during a test.

1.9 Engineered Safety Features - Features of a unit, other than reactor trip or those used only for normal operation, that are provided to prevent, iimit, or mitigate the release of radioactive material.

1.10 Experiment - An experiment is:

a. Any apparatus, device, or material placed in the reactor core region, in an experimental facility, or in line with a beam of radiation emanating from the reactor; or

b. Any operation designed to measure reactor characteristics.

1.11 Measuring Channel - A measuring channel is the combination of sensor, lines, amplifiers, and output devices which are connected for the purpose of measuring the value of a process variable.

1.12 Movable Experiment - A movable experiment is one where it is intended that the entire experiment or part of it may be moved in or near the core or into and out of the reactor while the reactor is operating.

1.13 Operable - A component or system is operable when it is capable of performing its intended function in a normal manner.

1.14 Operating - A component or system is operating when it is performing its intended function in a normal manner.

1.15 Operating Modes - The reactor operating modes are:

a. Mode 1 - Normal full power mode with a maximum nominal power level of $100 \mathrm{MW}$. Primary system pressurized above 575 psig and a ratio of percent nominal full power level to percent nominal full flow equal to or less than 1.3 .

b. Mode 2 - Low power operating mode with a maximum nominal power level of $2.5 \mathrm{MW}$. Primary system flow rate equal to or greater than 1,500 gpm; primary system may be depressurized.

c. Mode 3 - Critical experiment operating mode with a maximum nominal power level of $100 \mathrm{~kW}$. Neither system pressure nor forced coolant flow are required. 
1.16 Reactor Safety System - The reactor safety system is that combination of measuring channels and assoctated circuitry, which forms the automatic protective system of the reactor.

1.17 Reactor Secured - The reactor is secured when both fuel elements are removed or when all of the following conditions are satisfied:

a. Reactor shutdown.

b. The console switch is in the "OFF" position and the key is in proper custody.

c. No work is in progress involving in-core fuel handling.

1.18 Reactor Shutdown - The reactor is in a shutdown condition when all five control rods are fully inserted or when a reactivity condition equivalent to one where all control rods are fully inserted exists.

1.19 Reset Flux - A neutron flux signal which has been modified to agree with a calculated reactor heat power signal.

1.20 Safety Channel - A measuring channel in the reactor safety system.

1.21 Shutdown Margin - The amount of reactivity required to attain criticality from a given subcritical condition.

1.22 Time Intervals - In reference to surveillance or tests.

a. Annually - To be performed once each year at intervals not to exceed 14 months.

b. Semiannually - To be performed twice each year at intervals not to exceed 8 months.

c. Quarterly - To be performed four times each year at intervals not to exceed 5 months.

d. Monthly - To be performed once each month at intervals not to exceed 60 days.

c. Weckly - To be performed once cach weck at incervalo not to exceed 10 days.

f. Daily - l'o be performed once each day at intervals not to exceed ? days.

1.23 Tried Experiment - A tried experiment is:

a. An experiment previously performed in this reactor; or 
b. An experiment of simflar size, shape, composition, and location as an experiment previously performed in this reactor.

1.24 True Value - The exact value of a parameter at any instant. 


\section{SAFETY LIMITS AND LIMITING SAFETY SYSTEM SETTINGS}

\subsection{Safety Limits}

\subsubsection{Reactor Power and Reactor Coolant Flow, Coolant Temperature and Pressure}

Applicability:

This specification applies to the process variables of reactor power, flux (power) to flow ratio, reactor coolant flow, coolant temperature, and pressure.

\section{Objective:}

The objective is to set limits on critical process variables which, if not exceeded, will provide confidence that the integrity of certain of the physical barriers, which guard against the uncontrolled release of radioactivity, will not be breached. Specifications:

The safety limits on process variables shall be as specified in Table 2.1.

Table 2.1. Safety Limits on Process Variables

\begin{tabular}{|c|c|c|c|}
\hline \multirow[b]{2}{*}{ Process Variable } & \multicolumn{3}{|c|}{ Safety Limits } \\
\hline & Mode 1 & Mode 2 & Mode 3 \\
\hline $\begin{array}{l}\text { Reset neutron flux } \\
\text { (power) to flow } \\
\text { ratiol }\end{array}$ & $\begin{array}{l}1.37(@ \quad 16,000 \mathrm{gpm}) \\
2.40(@ \quad 1,500 \mathrm{gpm})\end{array}$ & None & None \\
\hline Neutron power & None & $4 \mathrm{MW}$ & $175 \mathrm{~kW}$ \\
\hline $\begin{array}{l}\text { Inlet coolant } \\
\text { temperature }\end{array}$ & $140^{\circ} \mathrm{F}$ & $140^{\circ} \mathrm{F}$ & None \\
\hline Covlant prcssurc 2,3 & 550 pcig & None & None \\
\hline Coolant flow ${ }^{2}$ & $1,350 \mathrm{gpm}$ & $1,350 \mathrm{gpm}$ & None \\
\hline
\end{tabular}




\section{Bases:}

For application to the quasi steady-state and steady-state operation of the HFIR, values for the safety limits (SL) were selected to meet the following criteria: With any given variable at its safety limtt, all other variables at their limiting safety system setting, and all uncertainties in the technical knowledge of the process resolved unfavorably, then the safety criteria selected (in the case of the HFIR, no hot spot burnout) should be satisfied. The criterion applicable to anticipated transients and accidents 1.s: No breach of the integrtity of the primary containment system concurrent with an accident or anticipated transient which results in hot spot burnout.

In order to ensure conservative results in the heat transfer analysis of the HFIR, numerous uncertainty factors are taken into account in the analysis (see Reference 1, pages 18,68, and 69). Application of these uncertainty factors guarantees that the calculated incipient boiling power levels and burnout power levels are truly minimum expected values. These uncertainty factors were chosen at the conservative limits, and it is unlikely that all would be at their extreme limit at the same point in the core. Details of the analysis for incipient boiling power level are documented in Reference 1; the method of calculating burnout power level is documented in References 2,3 , and 4 .

Based on conservative assumptions, the hot spot regions have been found to be confined to not more than $5 \%$ of the total fuel plate areas (see Reference 5, page 18). Detailed analyses giving the specific bases for selection of each of the safety limit values on the various process variables is given in Reference 4. 


\subsection{Limiting Safety System Settings (LSSS)}

\subsubsection{Reactor Power and Reactor Coolant Flow, Coolant Temperature and Pressure}

Appilcability:

This specification applies to the scram and other corrective action setpoints for the reactor process variables related to the safety limits.

\section{Objective:}

The objective of this specification is to provide limiting values for the setpoints of the safety channels so that automatic protective action w111 occur sufficient to provide confidence that the selected safety criteria (page 2-2) are satisfied.

\section{Specifications:}

The limiting safety system settings shall be as specified in Table 2.2.

Table 2.2. Limiting Safety System Settings for Process Variables

\begin{tabular}{|c|c|c|c|}
\hline \multirow[b]{2}{*}{ Process Variable } & \multicolumn{3}{|c|}{ Limiting Safety System Settings } \\
\hline & Mode 1 & Mode 2 & Mode 3 \\
\hline $\begin{array}{l}\text { Reset neutron flux } \\
\text { (power) to flow } \\
\text { ratiol }\end{array}$ & 1.3 (all flow rates) & None & None \\
\hline Neutron power & None & $3.25 \mathrm{MW}$ & $130 \mathrm{~kW}$ \\
\hline $\begin{array}{l}\text { Inlet coolant } \\
\text { temperature }\end{array}$ & $135^{\circ} \mathrm{F}$ & $135^{\circ} \mathrm{F}$ & None \\
\hline Coolant pressure 2,3 & 575 psig & None. & None \\
\hline Coolant flow ${ }^{2}$ & $1,500 \mathrm{gpm}$ & $1,500 \mathrm{gpm}$ & None \\
\hline $\begin{array}{l}\text { Rate of rise of } \\
\text { power }\end{array}$ & $20 \mathrm{MW} / \mathrm{sec}$ & None & None \\
\hline Main pump cutoff & 315 psig & $\mathrm{N} / \mathrm{A}$ & $\mathrm{N} / \mathrm{A}$ \\
\hline
\end{tabular}


Bases:

The limting safety system settings were selected at values such that, when measurement uncertainties and anticipated transient conditions are considered, there is confidence that the selected criteria (page 2-2) are satisfied. Detailed analyses, giving the specific bases for selection of each of the limiting safety system setting values on the various process variables are given in Reference 4 and in the Appendix (Accidents and Anticipated Transients). 


\subsubsection{Failed-Fuel-Element Detector}

Applicability:

This specification applies to the scram setpoint of the failedfuel-element detector.

\section{Objective:}

The objective of this scram is to limit the release of fission products should a breach occur in the fuel element cladding.

\section{Specifications:}

The LSSS for the failed-fuel-element detector shall be ten times the Mode 1 full power background radiation level at the detector chamber.

\section{Bases:}

Ionization chambers of the failed-fuel-element detector system monitor gross coolant activity as close to the core exit as possible. These chambers are not sensitive to small changes in fission product or contaminant activity due to the high level of the ${ }^{16} \mathrm{~N}$; however, this type of activity measurement is adequate to indicate a gross activity release and is the earliest indication from activity monitors available to the operator. This system will scram the reactor when there is significant increase in activity above the ${ }^{16} \mathrm{~N}$ background encountered at ful1-power operation. 
3. LIMITING CONDITIONS FOR OPERATION

\subsection{System Reactivity}

Applicability:

These specifications apply to the reactivity condition of the reactor and its associated components.

Objective:

The objective is to assure that the reactor can be made subcritical and maintained in a subcritical condition at all times. Specifications:

The reactor shall not be operated unless the anticipated and achieved start-of-cycle symetric critical rod position is greater than or equal to $16.3 \mathrm{in}$. withdrawn, and the water immersed shutdown margin of the fuel element is greater than or equal to $\$ 1.15$ with the following qualification: The reactor may be operated when the anticipated or achieved start-ofcycle symmetric critical rod position is less than $16.3 \mathrm{in}$. withdrawn, and/or when the water immersed shutdown margin of the fuel element is less than $\$ 1.15$; provided that, prior to continued operation, the shutdown capability for the Case IV configuration (as defined in Table 3.1) is checked by demonstrating that the reactor is just critical in a configuration known to be more reactive than the Case IV configuration.

Table 3.1. Cases for which Reactor Must Be Subcritical

\begin{tabular}{|c|c|c|}
\hline Case & Control Element Position & Flux Trap Condition \\
\hline I & All control elements fully inserted & Optimum void, nó target \\
\hline II & $\begin{array}{l}\text { Four control elements inserted, any } \\
\text { one control element fully with- } \\
\text { drawn }\end{array}$ & Optimum void, with target \\
\hline III & $\begin{array}{l}\text { Three-out-of-four scram from criti- } \\
\text { cal, the shim-regulating cylinder } \\
\text { immobilized }\end{array}$ & Optimum void, with target \\
\hline IV & $\begin{array}{l}\text { Three-out-of-four scram from criti- } \\
\text { cal, one shim-safety plate fully } \\
\text { withdrawn, the sh1m-regulating } \\
\text {.. cylinder immobilized }\end{array}$ & No void, with target \\
\hline
\end{tabular}


Bases:

The basic reactivity limitation criteria upon which the HFIR was designed and upon which operation is permitted is that given in Reference 5 (pages 88-91) which 1ists combinations of anticipated and abnormal events for which the reactor must be capable of being maintained in a subcritical condition. The detailed bases for selection of these criteria is discussed at length in Reference 5 (pages 88-91). Combinations of the events considered can be summarized into four significant cases, in each of which it is required that the reactor be capable of being maintained in a subcritical condition. This is shown in Table 3.1. The Case IV configuration is known to be more reactive than the Case I, II, and III configurations [Reference 5 (page 91, Table 1.c.9), Reference 6 (page 40, Table 11), and Reference 9 (page 44, Table 6.3)]. Hence, satisfying the subcriticality requirement for the Case IV configuration automatically satisfies it for the Case I, II, and III configurations.

Several special tests, measurements, and other evaluations are routinely conducted in order to assure that the provisions of this specification are always met for every HFIR operating cycle. Further, the specifications of Section 4.1 in these technical specifications relate to assuring compliance with this reactivity limitation specification. First, a reactivity measurement is made on every new HFIR fuel element in which the shutdown margin in the water-moderated and reflected condition is measured. The results of these measurements are used together with the results of critical experiments conducted in the HFIR facility (Reference 10, pages 15-17) as guidelines to ascertain whether a given core is reactive enough, when considered in combination with other relevant factors, to even closely approach the limit imposed by the Case IV subcriticality criterion. We have demonstrated, in the reactor, that a configuration known to be more reactive than the Case IV configuration is just critical for cores of several different reactivities. The results of some of these measurements are shown in Figure 3.1. It is evident frum these results that for any operating cycle in which the start-of-cycle symmetric critical rod position is in excess of $16.3 \mathrm{in.,}$ the Case IV subcriticality requirement is satisfied. Further, it has been demonstrated in the reactor that a fuel element having a water-immersed shutdown margin of $\$ 1.15$ 


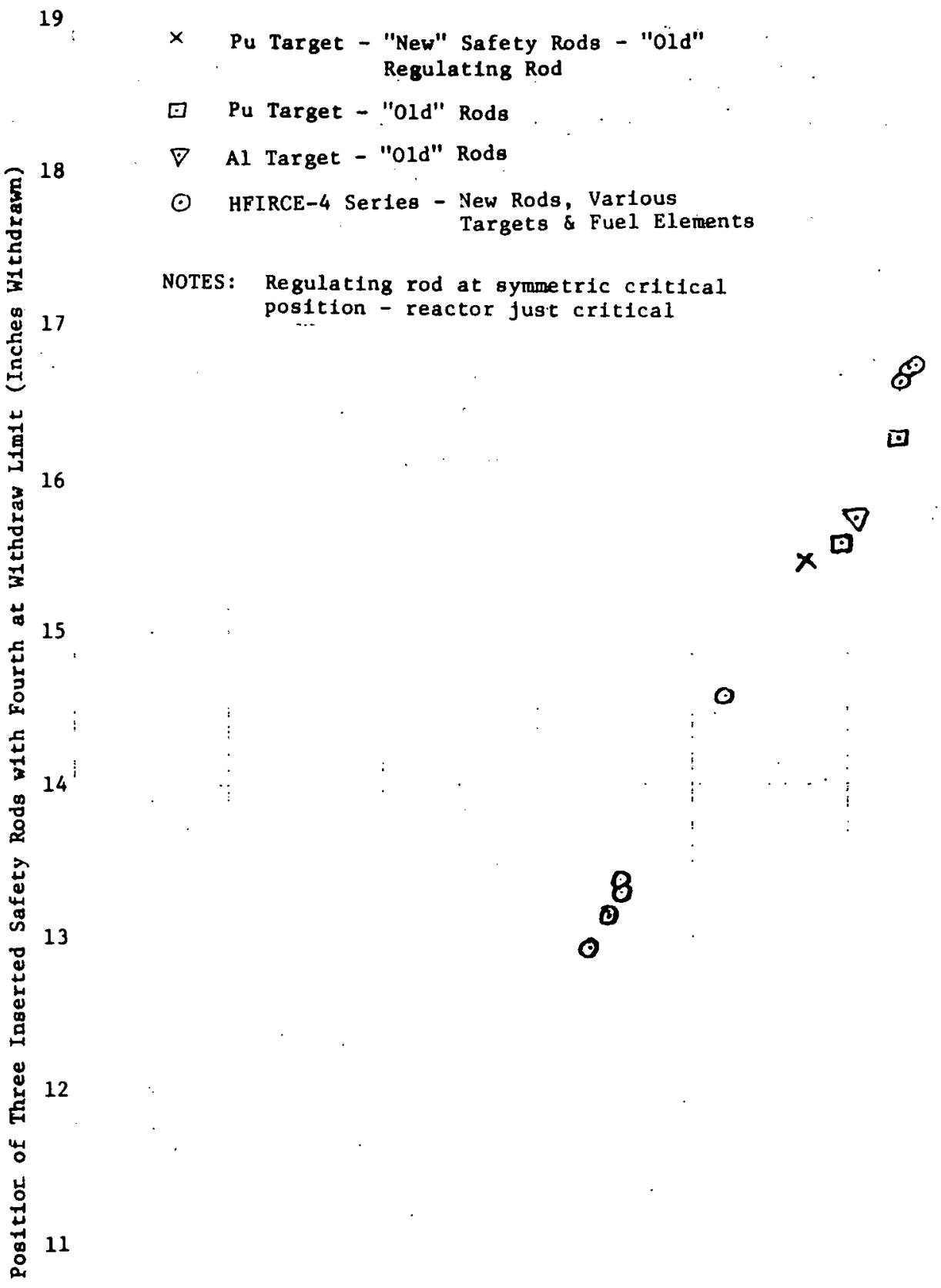

10 
satisfies the Case IV subcriticality criterion. Prior to continued operation, we will therefore demonstrate, for any anticlpated or achieved startof-cycle symmetric critical rod position less than $16.3 \mathrm{in.}$, or for any fuel element having a water-immersed shutdown margin of less than $\$ 1.15$, that the reactor is just critical in a configuration known to be more reactive than the Case IV configuration (see Section 4.1). Further, the prediction of the start-of-cycle symmetric critical rod position to within $\pm 0.5 \mathrm{in}$. for each fuel cycle using a new fuel element is required by these technical specifications (Section 4.1). Any significant anomaly which might affert system reactivicy would be recognized by comparioon of the actual to predicted start-of-cycle critical rod position. 


\subsection{Control System}

Applicability:

This specification applies to the amount of positive reactivity available to the servo control system and the rate at which that reactivity can be added to the reactor, by the servo control system.

Objective:

The objective is to ensure that the safety system can cope with any amount and rate of addition of positive reactivity by the servo control system.

\section{Specifications:}

The reactor shall not be operated unless the positive reactivity available to the control system is limited to the following values:

a. The amount of positive reactivity that the servo system is permitted to control is limited to $0.015 \Delta \mathrm{k} / \mathrm{k}$.

b. The maximum rate of reactivity addition by the servo system (regulating motor only) is limited to $0.00375 \Delta \mathrm{k} / \mathrm{k} \mathrm{sec}^{-1}$.

c. The maximum reactivity addition rate of all five shim elements is limited to $0.003 \Delta \mathrm{k} / \mathrm{k} \mathrm{sec}^{-1}$.

\section{Bases:}

The shim drive speed is $5.75 \mathrm{in.} / \mathrm{min}(0.096 \mathrm{in.} / \mathrm{sec})$, and the regu-

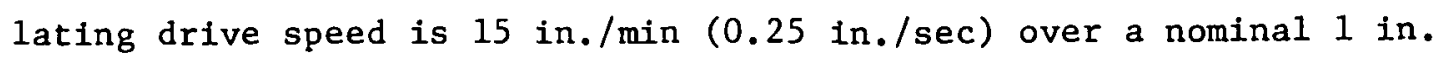
stroke. With the control elements initially at the clean core, symmetrical, critical position, the differential worth of the shim-regulating cylinder is $0.0119 \Delta \mathrm{k} / \mathrm{k}$ per inch and that of the set of four shim-safety plates is $0.0103 \Delta \mathrm{k} / \mathrm{k}$ per inch. For this initial control element position the maximum reactivity available to the servo system is a nominal 0.012 $\Delta \mathrm{k} / \mathrm{k}$ and the maximum rate at which it can be added under normal conditions is $0.0030 \mathrm{\Delta k} / \mathrm{k} \mathrm{sec}^{-1}$. With all five control elements being withdrawn at the shim drive speed, the maximum reactivity addition rate is 0.0021 $\Delta \mathrm{k} / \mathrm{k} \mathrm{sec}-\mathrm{l}$ for about $3 \mathrm{in.}$, after which it decreases.

Results (Reference 5, pages 75-80) from analog calculations made in connection with the control element reactivity accidents indicate that for 
beginning-of-cycle Mode 1 operation at full flow and full power and with the shim-safety plates in the least sensitive position (normally should not be in this position) $0.05 \Delta \mathrm{k} / \mathrm{k} \mathrm{sec}^{-1}$ can be inserted without the hotspot heat fiux exceeding the burnout heat flux. The hot-spot peak plate temperature calculated for this case was on $1 y 450^{\circ} \mathrm{F}$, and the total energy released during the brief transient was about $11 \mathrm{MW}$ sec (this includes all energy generated during the transient).

Starting from low power $(<100 \mathrm{~kW})$ and full flow (Mode 1$)$, the selfshutdown mechanisms alone limited the peak heat flux to less than the burnout heat flux, when reactivity was added at the rate of $0.005 \mathrm{\Delta k} / \mathrm{k}$ $\sec ^{-1}$. The peak power in this case was only $170 \mathrm{MW}$, and the toral energy release was less than $10 \mathrm{MW}$ sec. 


\subsection{Shim-Safety Plates}

Applicability:

This specification applies to the shim-safety plate time-of-flight and to the magnet release time.

Objective:

The objective is to ensure proper performance of the shim-safety plates during reactor operation and during reactor scram. Specifications:

a. The reactor shall not be operated unless the maximum t1me-offlight (measured from initiation of the scram signal to seating of the plate from its fully withdrawn position) for any shimsafety plate 18 no greater than $450 \mathrm{msec}$.

b. The reactor shall not be operated unless the magnet release time, measured by tripping all three channels, is no greater than 12.0 msec.

Bases:

Any significant obstruction of the shim-safety plates or any misoperation of the shim-safety plate release mechanism would result in a time-of-flight measurement much greater than $450 \mathrm{msec}$. Thus, limfting the maximum permitted time-of-flight to $450 \mathrm{msec}$ helps ensure proper functioning of the shim-safety plates.

A magnet release time of $12.0 \mathrm{msec}$ measured using our standard microswitch method of measurement corresponds to an actual magnet release time of less than $10.0 \mathrm{msec}$ (References 11 and 12). A magnet release time of $10 \mathrm{msec}$ was used in the analyses of Modes 1 and 2 reactivity transients reported in the HFIR accident analysis (Reference 5, page 77). 


\subsection{Reactor Control and Safety Systems}

\section{Applicabllity:}

This specification applies to the safety, control, and surveillance instrumentation required for startup and operation of the reactor.

\section{Objective:}

The objective is to ensure an adequate complement of safety, control, and surveillance instrumentation during reactor startup and operation.

\section{Specifications:}

a. The minimum complement of reactor safety and measuring instrumentation required for a reactor startup in the varlous modes of operation is specified in Table 3.2.

b. The minimum complement of reactor safety and measuring instrumentation required for reactor operation in the varlous modes is specified in Table 3.3.

c. When one of the three safety channels is out of service, it will be tripped except for test intervals.

\section{Bases:}

The reactor control and safety systems utilize three channels of instrumentation with the concurrence of lwo of the thrae safety shannels required for corrective action (scram) and, in most cascs, with concurrence of Lwu out of three of the control channels required for an action by the coinerol system. When one of the three safety channels is out of service, it will be tripped so that the remalning two channels operate as a one-out-of-two safety system except for test intervals as specificd in Section 6.9 , During short tesc intervals, it is pcrmissible to take the inoperable channel out of trip so that the other two channels may be tested. The uystem oprintes in a two-out-of-two mode during the short test interval. Control and/or safety action occurs whenever certain predetermined conditions exist, and usually the control and safety action is preceded by an alarm.

A minimum of two operable neutron flux safety channels is required for both startup and operation in all modes to provide monitoring of 
Table 3.2. Minimum Reactor Instrumentation

Required for Startup

\begin{tabular}{|c|c|c|c|}
\hline & \multicolumn{3}{|c|}{ Number Required } \\
\hline Description & Mode 1 & Mode 2 & Mode 3 \\
\hline \multicolumn{4}{|c|}{ Safety Instrumentation } \\
\hline Neutron flux channel & 2 & 2 & 2 \\
\hline Primary coolant flow channe1 & 2 & 2 & 0 \\
\hline Heat power channel & 2 & 0 & 0 \\
\hline Reactor inlet temperature channel & 2 & 2 & 0 \\
\hline Primary coolant pressure channel & 2 & 0 & 0 \\
\hline Failed-fuel-element detector channel & 2 & 2 & 0 \\
\hline Power rate-of-rise channel & 2 & 0 & 0 \\
\hline Main pump cutoff & 2 & 0 & 0 \\
\hline \multicolumn{4}{|c|}{ Measuring Instrumentation } \\
\hline Counting rate channel & 2 & 2 & 2 \\
\hline Servo channel & 2 & 0 & 0 \\
\hline Reactor bay containment flow monitor & 1 & 1 & 1 \\
\hline Closed off-gas system vacuun mónitor & 1 & 0 & 0 \\
\hline Instrument air system pressure monitor & 1 & 1 & $1 \cdot$ \\
\hline
\end{tabular}


Table 3.3.- Minimum Reactor Instrumentation

Required for Operation

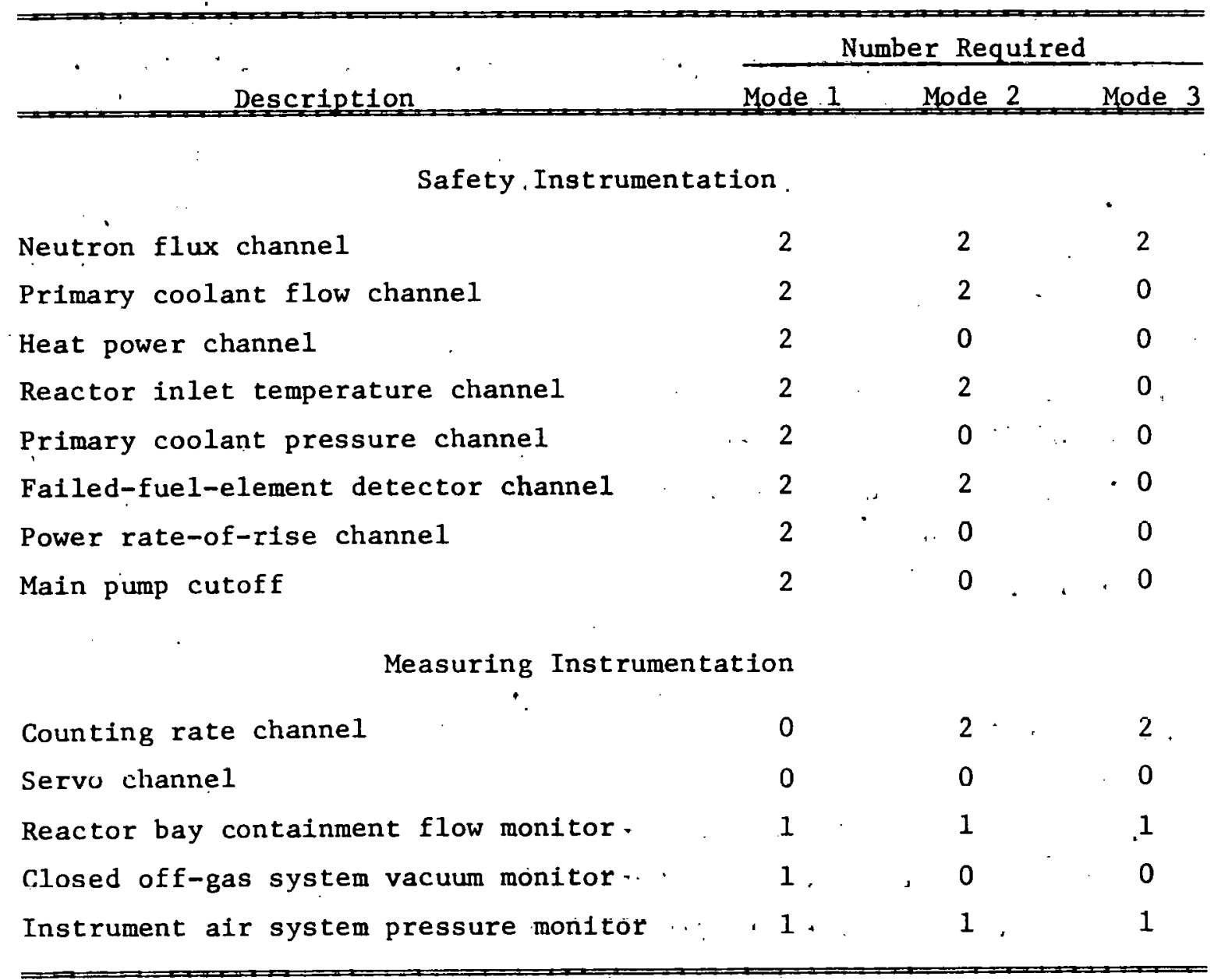


the flux (power) level and to provide safety action if required via the flux-to-flow scram (Mode 1) or the neutron power scram (Modes 2 and 3 ). A minimum of two operable primary coolant flow safety channels is required for both startup and operation to provide flow monitoring in Modes 1 and 2, to provide safety action if required in Mode 1 via the flux-to-flow scram, and to provide safety action if required in Mode 2 via the low coolant flow scram. Mode 3 is a convective flow mode where neither flow monitoring nor flow-related safety action is required or provided; hence, operable coolant flow channels are not required in this mode.

A minimum of two operable heat power safety channels is required for both startup and operation in Mode 1 to provide the calibration signal for resetting the flux gain in the flux-to-flow safety channels. They are also required to provide an upper limit on reactor power (120-MW scram) resulting from slow transients which is lower than that provided by the flux-to-flow channels. They also provide redundancy in monitoring reactor power. Flux-reset is not provided in the flux-to-flow channels in Modes 2 and 3, and the 120-MW scram provides no protection in Modes 2 and 3. Hence, operable heat power channels are not required for Modes 2 and 3 . A minimum of two operable reactor inlet temperature safety channels is required for both startup and operation in Modes 1 and 2 (forced coolant flow modes) for monitoring inlet coolant temperature and to provide safety action (scram) if the inlet coolant temperature reaches its safety system setting. Mode 3 is a convective flow mode of operation where neither inlet coolant temperature related safety action nor monitoring is required. Hence, uptrable inlet coolant cemperature channels are not required for Mode 3.

A minimum of two operable primary coolant pressure safety channels is required for both startup and operation in Mode 1 to provide reactor scram in the event of a system coolant pressure less than its safety system setting. Operation in Modes 2 and 3 is unpressurized; hence, operable printary cuolant pressure channels are not required in these modes. 
A minimum of two operable falled-fuel-element detector safety channels is required for both startup and operation in Modes 1 and 2 in order to shut down the reactor in the event there is a significant increase in radloactivity above the ${ }^{16} \mathrm{~N}$ background encountered at full power as described in the "Bases" of Section 2.2.2. Since forced coolant flow is required for proper functioning of these channels and Mode 3 is a convective flow mode, operability of these channels is not required in Mode 3.

A minimum of two operable power rate-of-rise safety channels is required for both startup and operation in Mode 1 in order to provide reactor scram capability in the event of accidental positive reactivity insertions. Rate trips are not required in Modes 2 and 3 (see page $\mathrm{A}-2$ in the Appondix of this incument).

A minimum of two operable main pump cutoff channels is required in Mode 1 to provide main punp cutoff following scram upon loss of system pressure as discussed in the Appendix.

A minimum of two operable counting rate channels $1 \bar{s}$ required fur startup in all operating modes, and for operation in Modes 2 and 3 to provide monitoring of the neutron generation rate in the reactor from source level and to provide monitoring of the power level. These channels also provide certain control and interlock functions. Operable counting rate channels are not required for Mode 1 operation (except for startup) because their functions are performed by other required instrument channe1s.

A minimum of two operable servo channels are required for startup in Mode 1 to monitor and control the automatic startup mode. Operability of these channels is not required for startup in Modes 2 or 3 because the system design provides for manual startup, nor are operable servo channels required for operation in any of the three operating modes, since the system design provides for manual operalion in all three mudes.

One operable reactor bay contalnment flow monitor is required for both startup and operation in all modes to provide monitoring of the building exhaust rate to assure that in-leakage is maintained into the reactor bay.

One operable closed off-gas system vacuum monitor is required for startup and operation in Mode 1 because in this operating mode the letdown 
system deaerator exhaust gases are routed into the closed off-gas system. Operability of this monitor is not required for startup or operation in Modes 2 or 3 because the letdown system is not in operation in these modes. One operable instrument air system pressure monitor is required for startup and operation in all modes for monitoring instrument air pressure to assure that all pneumatic instrumentation in the reactor control and other systems have sufficient air supply to function properly. 


\subsection{Special Building Hot Exhaust (SBHE) Filter Efficiency}

\section{Applicability:}

This specification applies to the special building hot exhaust (SBHE) fllter efficiency for elemental lodine and particulate material.

\section{Obfective:}

The objective is to ensure that exposures to the public resulting from the release of radioactive effluents do not exceed the guldelines set by ERDA Manual Chapter 0524 for unrestricted areas.

\section{Specifications:}

The minimum efficiency for the filter system which filters the SBHE effluent shall be:

a. $99.5 \%$ for particles larger than $0.3 \mu$; and

b. $99 \%$ for elemental iodine.

\section{Bases:}

Based on the analysis of the maximum credible accident at the HFIR (Reference 5, page 24), an iodine decontamination factor of only 7 is required from filters to satisfy the requirements imposed by the Advisory Committee on Reactor Safeguards. The actual minimum efficiency specified, $99 \%$, represents a decontamination factor of 100 . Nonvolat1le flssiui products are less mobile than the iodines. It was shown thal a decontamination factor of 200 by the absolute filters was more than sufficient to meet the imposed requirements. The actual minimum efficiency specified, $99.5 \%$, represents a decontamination factor of 200 . 


\subsection{Containment}

Applicability:

This specification applies to the operability of the special building hot exhaust (SBHE) system.

\section{Objective:}

The objective of this specification is to ensure the operability of the SBHE system during all modes of reactor operation and irradiated.fuel handling.

\section{Specifications:}

The following containment system requirements are necessary for reactor operation in Modes 1, 2, and 3 and during in-pool handling of irradiated fuel elements:

a. In-leakage into the reactor bay will be maintained during operation by means of the SBHE system consisting of fans, ducts, filters, and the 250-ft-high stack.

b. The minimum exhaust rate from the reactor bay shall be sufficient to maintain in-leakage through all building openings but shall not be less than 6,000 cfm.

c. There must be at least one operating SBHE fan and at least one standby SBHE fan.

d. Emergency power from a start-on-demand-diesel-electric generator must be available to the fans.

e. The minimum number of operable letdown block valves shall be one each for each of the three heat exchangers in operation. (This applies to Mode 1 operation only.)

\section{Bases:}

The potential radiation exposure to persons at the site boundary and beyond has been calculated following an accidental release of fission product activity (Reference 5, pages 23-26). These calculations were based on the proper operation of the SBHE system to maintain the reactor bay at a negative pressure and to direct all effluents through filters and up the facility stack. Critical equipment in the SBHE system is duplicated to ensure its proper operation. 
The SBHE system is In normal operation during all modes of reactor operation and irradiated fuel handling. No valves or switches are required to operate to place the system in "containment" status. All air leaving the reactor bay is passed through high efficiency particulate filters capable of removing $99.5 \%$ of particles larger than $0.3 \mu$ and through charcoal filters which remove at least $99 \%$ of any elemental iodine.present before discharging the alr to the facility stack. This system assures filtering and dilution of gaseous effluents before they reach personnel either on- or off-site.

Routine tests have shown that a minimum exhaust rate of $6,000 \mathrm{cfm}$ from the reactor bay produces sufficient negarive pressure tu ensure in.. leakage. 


\subsection{Primary Coolant System}

\section{Applicability:}

This specification applies to the operating conditions of the primary coolant system for Mode 1 operation.

Objective:

The objective is to ensure that the operating conditions of the primary coolant system remain within the bounds of the system design parameters.

\section{Specifications:}

The following conditions are limits on the operation of the primary coolant system:

a. Maximum allowable operating pressure: 1,000 psig

b. Minimum number of operable pressure relief valves:

\begin{tabular}{|c|c|c|c|}
\hline $\begin{array}{c}\text { Number } \\
\text { of } \\
\text { Valves }\end{array}$ & $\begin{array}{l}\text { Spring } \\
\text { Setting } \\
\text { (psig) }\end{array}$ & $\begin{array}{c}\text { Relief } \\
\text { Pressure } \\
\text { (psig) } \\
\end{array}$ & $\begin{array}{l}\text { Minimum } \\
\text { Capacity } \\
\text { (gpm) }\end{array}$ \\
\hline 1 & 1,025 & 1,100 & 250 \\
\hline 1 & 975 & 1,050 & 30 \\
\hline
\end{tabular}

c. Maximum vesse 1 bulk outlet water temperature: $200^{\circ} \mathrm{F}$

d. Maximum differential pressure across reactor vessel: 150 psi

e. Minimum water temperature with system pressurized: $70^{\circ} \mathrm{F}$

f. An operable pressurizer pump cutoff on high pressure: $\leq 900$ psig

Bases:

The primary coolant system and pressure vessel were designed in accordance with Section VIII of the 1962 ASME Boiler and Pressure Vessel. Code and Nuclear Code Cases 1270N, 1271N, and 1273N. The design conditions were $1,000 \mathrm{psig}$ at $200^{\circ} \mathrm{F}$. To verify the adequacy of the primary coolant system, hydrostatic tests at 1,550 psig and supplementary tests at 1,000 psig following 17 cycles from atmospheric pressure to 1,000 psig were performed.

In-vessel reactor components were designed to withstand the applicable combination of loads, including a 125 psi pressure drop, hydraulic loads, dead weight, and any extra loads resulting from control drive malfunction. Mechanical and thermal stresses were analyzed and found in all cases to be well within the elastic limits. The maximum permitted differential 
pressure of 150 psi across the reactor vessel includes the 125 psi drop across the components and the additional pressure losses encountered in the vessel flow distributors, inlet and exit nozzles, inlet and exit piping, and the primary coolant strainer.

The sizing of nozzle openings and the arrangement of the water annulus outside the core have been designed to limit the fast neutron dose to the pressure vessel. On this basis, vessel materials were used which assure that the nil ductility temperature, as determined by Charpy V-notch impact tests, of any portion of the vessel will not exceed $+10^{\circ} \mathrm{F}$ after 20 years of operation (keference 16, page 5-7). To provide additional hoadroom above this temperature, an administrative limit of $70^{\circ} \mathrm{F}$ has been established as a minimum temperature for primary system pressurization.

Article 9 of Section III of the 1962 ASME Boiler and Pressure Vessel Code requires that the pressure relieving devices installed to protect the system be of sufficient capacity to prevent a pressure rise in the system of greater than $10 \%$ above the design pressure. In addition, at least one valve must relieve at a pressure not greater than design pressure, while all others must relieve at pressures not greater than $105 \%$ of design pressure. For the HFIR primary coolant system these limits are:

a. Maximum pressure: 1,100 psig

b. Maxinum set pressure (one valve): 1,000 psig

c. Maximum set pressure (remaining valve): 1,050 psig

Capacity of the pressure relief valves must be sufficient to prevent overpressure with the sole source of overpressure being the capacity of the pressurizer pumps. The setting, relief pressure, and capacity of the pressure relief valves meet these criteria. .

An operable pressurizer pump cutoff on high pressure is required to preclude inadvertent pressurization of the primary system due to misoperation or maltunction of the pressurizer pump. 


\subsection{Limitations on Experiments}

Applicability:

This specification applies to all experiments installed in the HFIR. Objective:

The objective of this specification is to establish general limits for HFIR experiments which will protect the reactor from damage and will limit radiation exposures to both on-site and off-site personnel to as low as practicable levels.

\section{Specifications:}

\section{a. In-Reactor Experiments}

The following limitations apply to all in-reactor experiments:

\section{(1) Reactivity}

The following limits apply to individual experiments:

(a) Experiments which can cause a positive reactivity change greater than $0.005 \Delta \mathrm{k} / \mathrm{k}$ and which are movable experiments shall be equipped with a mechanical insertion and removal system having the same reliability as the reactor control system drives. The reactivity insertion rate by these mechanisms shall not exceed 0.00025 $\Delta \mathrm{k} / \mathrm{k} \sec ^{-1}$.

(b) Experiments which can cause a positive reactivity change greater than $0.005 \Delta \mathrm{k} / \mathrm{k}$ due to motion but which need not be moved while the reactor is critical shail be so firmly supported that no credible circumstances can cause them to be moved while the reactor is critical.

(c) Experiments which can cause a positive reactivity change greater than $0.005 \Delta \mathrm{k} / \mathrm{k}$ due to being damaged by temperature or pressure shall. be instrumented to cause a reactor shutdown if such temperature or pressure is approached. This is in addition to the safeguards built into the experiment to control the temperature and/or pressure. 
(d) No experiment may be allowed to cause a reactivity change equivalent to or greater, in effect, than a 1-sec ramp insertion of $0.05 \Delta \mathrm{k} / \mathrm{k}$.

(2) Hydraulic Stability

All in-tank experiments shall be designed to withstand the hydraulic forces exerted by the reactor coolant. Bolts, nuts, and screws used in assembly shall be staked, welded, or similarly held to avold loss into the reactor.

(3) Temperature

Heat developed in any experiments by gamma ahsorption, fissions, electric heaters, etc., shall be dissipated by an adequate coolant flow. Under normal conditions, the temperature of the outer container shall not exceed the saturation temperature of the reactor coolant.

(4) Explosives

No explosives or mixtures of materials which under credible circumstances can detonate shall be irradiated in the reactor.

(5) Pressure Containment

Where fallure of pressure-containing wails of an experiment can cause a hazard to personnel or to the reactor, the container must meet the intent of applicable pressure vessel codes. The design for each such container must be reviewed by an appropriate competent engineer and written approval obtained by the Operations Division and the Reactor Experiment Review Committee (RERC).

b. Beam-Tube Experiments

The following additional limttations apply to all experiment devices installed in the horizontal beam tubes:

(1) Experiments shall be designed such that no significant leakage would result if the beam tube internal pressure were 1,000 psig.

(2) Experiments shall be designed such that rupture of the beam tube inside the reactor followed by fallure of the beam-tube 
outer flange would not result in a leakage flow rate greater than $100 \mathrm{gpm}$ at $1,000 \mathrm{psig}$ differential pressure.

(3) An experiment or plug designed to limit leakage to $100 \mathrm{gpm}$ at 1,000 psig differential pressure shall be in place at all times when the reactor is operating in the pressurized condition.

Bases:

\section{a. In-Reactor Experiments}

(1) Reactivity

(a), (b), and (c) The upper limit of $0.005 \Delta \mathrm{k} / \mathrm{k}$ for a reactivity change by an experiment ensures that such change will not result in prompt criticality. It also ensures that the servo system can immediately compensate for such change. The limit of $0.00025 \Delta \mathrm{k} / \mathrm{k} \mathrm{sec}^{-1}$ for an intentional, controlled reactivity insertion rate ensures adequate compensation by the servo system.

(d) Limiting the reactivity change rate to a $1-\mathrm{sec}$ ramp insertion of $0.05 \Delta \mathrm{k} / \mathrm{k}$, even for the failure case, ensures that fuel hot-spot melting will not occur during the resulting transient (Reference 5, page 79).

(2) Hydraulic Stability

The reactor components must be protected from damage that might result from an experiment which moves in an uncontrolled manner due to hydraulic forces. Any bolts, nuts or other items lost from an experiment could conceivably damage reactor components or block coolant flow paths.

(3) Temperature

As with reactor components, the surfaces of experiment rigs are maintained below the saturation temperature of the reactor coolant to avoid steam blanketing and possible burnout.

(4) Explosives

The irradiation of explosives is avoided to protect reactor components from possible damage. 
(5) Pressure Containment

Fallure of pressure-containing walls could affect reactivity or damage adjacent reactor components. Fallure of pressure-containing walls external to the reactor may endanger personnel directly by impact injury or. release of radioactive gases.

b. Beam-Tube Experiments

(1) The design of beam-tube experiments must be such that they meet the requirements of other components of the reactor primary containment system.

(2) The reactor pressurizer pumps can maintain the primarysystem pressure at the required safe operating value if the leakage rate does not exceed $100 \mathrm{gpm}$. 


\subsection{Emergency Core Cooling}

Applicability:

This specification defines the emergency core cooling requirements

for Mode 1 operation.

Objective:

The objective of this specification is to ensure adequate post-shutdown core cooling.

Specifications:

At least two battery-powered pony motor pumps must be in service at all times during reactor operation in Mode 1 . Each unit must be capable of pumping 1,000 $\mathrm{gpm}$ for at least two hours.

Bases:

In order to prevent the heat flux of nearly expired HFIR fuel elements from exceeding incipient boiling immediately after shutdown from 100-MW operation, it is necessary that the coolant filow rate be about $7 \%$ of normal full flow for at least 83 minutes. After this time the fission product decay energy drops below $1 \mathrm{MW}$ and natural convection cooling is sufficient to prevent incipient boiling in the core. Any one battery-powered pony motor can pump 1,000 $\mathrm{gpm}, \sim 7 \%$ of normal full flow, for more than two hours, but two are required for Mode 1 operation to ensure a post-shutdown coolant supply. 


\subsection{Emergency Shutdown System}

\section{Applicability:}

This specification defines the capabilities of the backup shutdown system required for reactor operation in Mode 1.

\section{Objective:}

The objective of this specification is to ensure the availability of an adequate emergency shutdown system any time the reactor is operating in Mode 1.

\section{specificatiuny:}

A backup shutdown system using cadmium nitrate will be operable any time the reactor is operating at power levels above $10 \mathrm{MW}$.

a. Operating procedures governing recovery from power reductions shall be such that the power level will not exceed $130 \mathrm{MW}$ as a result of xenon burnout if the control rods become immobilized during the recovery. The procedures shall be based on normal Mode 1 operating conditions.

b. Operating procedures covering recovery from power reductions shall allow the operator a minimum of $11 / 2$ minutes from the time the power level exceeds the desired power level by $2 \%$ for investigation of the reason and, if necessary, actuation of the control valves for the poison injection system. This time allowance is in addition to that required for the backup system to operate.

c. The quantity of cadmium avallable for infecting into the primary system shall be at least 276 lbs.

\section{Bases:}

Operating procedures have been developed which call for a stepped escalation of reactor power after a power reduction or shutdown. These procedures, which are based on the neutronic behaviur during a restart in which xenon is being burned out, allow time for the injection of the poison following recognition of the fact that the rods have become inoperable without permitting the reactor power level to exceed $130 \mathrm{MW}$. 
The restart procedures assume a delay of $21 / 2$ minutes between occurrence of the stuck rod condition and the time the poison reaches the core. The overall time response for poison injection is made up of the recognition time, the valve operating time, and the time required for the poison to reach the core following operation of the valves. It is estimated that no more than 5 seconds would be required for the operator to actuate the control valves once the decision has been made to inject poison. The time required for the valves to shift position following actuation from the control room is less than 5 seconds. The time required for the poison to reach the core following valve actuation is less than 45 seconds. This gives a total of 55 seconds or $\sim 1$ minute. The rest of the assumed $21 / 2$ minute delay is assigned to recognition that a problem exists which requires poison injection.

The first step in recognition requires that the operator observe that the reactor is departing from the desired power level. To help provide this information, an annunciator is connected to the relay matrix which monitors the servo error signal. This error monitor actuates before the reactor power exceeds the desired level by $2 \%$ and therefore the operator's attention is directed to the possibility of trouble before much increase in power level has occurred. A false alarm can be easily detected by attempting to insert the control elements using the several methods available. If none of the methods are successful (reduction of the servo demand, insertion of one rod, reverse, air motor reverse, or scram), the next step is the injection of the poison. It is estimated that no more than 30 seconds would be required to try all of the methods mentioned; however, $11 / 2$ minutes are provided in order to ensure adequate time for vertfication.

Based on experiments at the HFIR using soluble boron to poison the core (Reference 9, page 40) and calculations (Reference 13), 276 1bs of cadmium evenly distributed in the primary coolant system is sufficient to maintain subcriticality in a new core with all control rods fully withdrawn. Actually, 290 lbs of cadmium is available in the form of a 44 wt \% solution of 800 lbs of $\mathrm{Cd}\left(\mathrm{NO}_{3}\right)_{2} \cdot 4 \mathrm{H}_{2} \mathrm{O}$ dissolved in water to make $\sim 110$ gallons of solution. Piping for the poison injection system contains an 
orifice to limit the flow rate of poison from the storage tank to the pressurizer pump header to $\sim 1$ gallon per second. This flow rate will require $\sim 110$ seconds for the injection of the $\sim 110$ gallons of solution. The primary coolant loop time is about 48 seconds; so the poison would be injected over approximately two passes of the primary coolant and thus ensures reasonable mixing during the period of injection. 


\subsection{Water Height Above Core}

Applicability:

This specification applies to the height of water required above the core centerline in the various modes of reactor operation.

Objective:

The objective is to ensure an adequate height of water above the fuel element for radiation shielding during reactor operation.

Specifications:

The following minimum heights of water shall be maintained above the core centerline in the various modes of operation:

Mode $125 \mathrm{ft}$

Mode $2.25 \mathrm{ft}$

Mode $3 \quad 10 \mathrm{ft}$

\section{Bases:}

The original shielding calculations and subsequent measurements (Reference 16, pages 9-1 and 9-2) have shown that the specified heights of water are more than adequate to prevent excessive radiation fields at the point of closest personnel access in Modes 1 and 2 operation.

Measurements reported in Reference 15 (pages 9 and 10) indicate that at full power of $100 \mathrm{~kW}$ in Mode 3, the gamma exposure rate through $10 \mathrm{ft}$ of water (i.e., at the point of closest possible personnel access) will be in the order of several $\mathrm{R} / \mathrm{hr}$ and the neutron dose rate is negligible. Radiation level is monitored and access to the area is carefully controlled while operating in Mode 3 with lower than normal water levels. 
3.12 Installation of Target or. Its Equivalent in the Flux Trap

\section{Applicability:}

This specification applies to the requirement that the target or 1ts equivalent be installed in the flux trap.

\section{Objective:}

The objective is to assure that the reactor will not be operated without a target or its equivalent in the flux trap.

\section{Specitications:}

The reactor shall not be operated unless the target or lls equlvalent is installed in the flux trap.

Bases:

Operation without the target or its equivalent in the flux trap would involve the potential for introduction of larger amounts of reactivity through the introduction of voids into the flux trap region than is possible with the target installed. In the analysis of reactivity accidents in the accident analysis report (Reference 5, page: 81), It was assumed that the target was installed in the flux trap. Reactivity accidents resulting from flux trap volding would be more severe, without the targer or its equivalent installed, than those analyzed in the accident analysis repurt. 


\subsection{Radiation Monitoring Equipment}

\section{Applicability:}

This specification applies to the monitoring of radiation levels and airborne activity in the reactor building.

\section{Objective:}

The objective is to ensure a sufficient number and variety of operable instrumentation to adequately monitor radiation levels throughout. the building.

Specifications:

The reactor shall not be operated unless the following minimum requirements for operable area radiation monitors are met or backup measures suitable to the reactor supervisor or his designated alternate are provided:

a. At least one operable constant air monitor shall be located on each of the three lower floors of the reactor building.

b. At least one operable monitron shall be located on each of the three lower floors of the reactor building.

c. The above mentioned equipment shall provide remote indication in the reactor control room.

\section{Bases:}

The minimum required number of radiation monitors on each of the lower floors of the building provides protection and warning of impending or existing danger from radiation so that there will be sufficient time to evacuate the building or portions of the building and to take necessary steps to prevent the spread of radioactivity to the surroundings.

Remote indication in the control room provides continuous information of the radiation levels within the building. 


\subsection{Core Components}

\section{Applicability:}

This specification applies to the structural integrity of the reactor components.

Objective:

The objective is to ensure that the integrity of the reactor components is consistent with safe, rellable reactor operation. Specifications:

The reactor shall not be oporated with known structurally unsafe reactor components.

\section{Bases:}

The reactor components are designed to withstand the applicable combination of loads, including a 125 psi pressure drop, hydraulic loads, dead weight, and any extra loads resulting from control drive malfunctions. Mechanical and thermal stresses have been analyzed and found in all cases to be well within the elastic limits (Reference 16, page 5-5). 


\subsection{Emergency Power}

Applicability:

This specification applies to the emergency power required for startup and operation of the reactor.

Objective:

The objective is to ensure that an operable emergency source of power be available during reactor operation.

\section{Specifications:}

a. The reactor shall not be operated unless at least one emergency diesel-generator is operable.

b. The reactor shall not be operated unless the switchgear battery bank is operable.

\section{Bases:}

The HFIR is equipped with two emergency diesel-generators, each of which supplies power to different SBHE and HOG system fans to provide building containment. Containment is maintained during a normal power outage as long as one of the diesel-generators is operable. 


\section{SURVEILLANCE REQUIREMENTS}

\subsection{System Reactivity}

Applicability:

This specification applies to the surveillance requirements for system reactivity.

\section{Objective:}

The objective is to assure compliance with the specifications set forth in section 3.1 relating to system reactivity.

\section{Specifications:}

a. Shutdown capability shall be checked for the Case IV configuration (as defined in Table 3.1, page 3-1) by demonstrating that the reactor is just critical in a configuration known to be more reactive than the Case IV configuration prior to continued operation, for an anticipated or achieved start-of-cycle symetric critical rod position of less than 16.3 in., and/or when the water immersed shutdown margin of the fuel element is less than $\$ 1.15$.

b. A reactivity measurement shall be made on every new HFIR fuel element in which the shutdown margin in the water-immersed condition is measured.

c. The start-of-cycle symetric critical rod position will be predicted to within $+0,5 \mathrm{in}$. for each fuel cycle using a new fuel element. This requirement will not apply to infrequent fuel cycles using partially burned fuel elements. Failure to predict the start-of-cycle symetric critical rod position to within \pm 0.5 in. will not constitute a violation of these technical specifications but will impose a further requirement that the situation be evaluated in order to continue operation of the reactor.

Bases:

The above specified checks, measurements, predictions, and evaluations, at the specified frequencies, provide adequate assurance of compliance with the specifications set forth in Section 3.1. 


\subsection{Control System}

\section{Applicab1lity:}

This specification applies to the surveillance requirements on the amount of positive reactivity available to the servo control system and on the rate at which that reactivity can be added to the reactor by the servo control system.

\section{Objective:}

The objective is to assure compliance with the specifications set furlh la Section 3.2 .

\section{Specifications:}

The speeds of the shim and regulating drive motors w11l be measured at least annually.

Bases:

Measurement of the drive motor speeds at the specified frequency adequately assures that reactivity addition rates by the servo control system will not significantly increase as a consequence of changes in drive motor speeds. Perlodic measurement of the differential rod worth is not considered necessary for the following reasons. First, all new HFIR rods are essentially 1dentical and the fuel element and core configuration in the HFIR is highly standardized. Further, variations in poison content with rod irradiation and consequent rod worth changes are sufficiently small and sufficiently well understood such that potential noncompliance with the specifications of Section 3.2 attributable to this mechanism can be ruled out. In addition, any significant anomaly in rod worth which might occur for some unknown reason should be recognized by comparison of the actual to predicted start-of-cycle symmetric critical rod position required by Section 4,1 of these technical specifications. 


\subsection{Shim-Safety Plates}

Applicability:

This specification applies to the surveillance requirements for shimsafety plate time-of-flight and magnet release time.

Objective:

The objective is to assure compliance with the specifications set forth in Section 3.3.

Specifications:

a. Shim-safety plate time-of-flight (from the fully withdrawn position to seating of the plate) shall be measured prior to startup following each refueling of the reactor and following any shim-safety plate maintenance which might affect the time-offlight.

b. Magnet release time shall be measured prlor to startup for each fuel cycle and following any shim-safety plate maintenance which might affect the magnet release time. The test prior to the startup for each fuel cycle may be conducted either before or after refueling of the reactor.

Bases:

To ensure that the shim-safety plate stroke is unobstructed and that they are capable of performing properly, the time-of-flight must be measured prior to startup following each refueling of the reactor and following any shim-safety plate maintenance which might affect the timeof-flight.

Operating experience has demonstrated that the specified frequency for measuring magnet release time is adequate to assure compliance with the applicable specification set forth in Section 3.3. Further, this represents the highest practicable measurement frequency from the standpoint of operating continuity. Measurement prior to startup for each fuel cycle either before or after refueling is adequate since refueling the reactor does not affect magnet release time. 


\subsection{Reactor Control and Safety Systems}

\section{Applicability:}

This specification applies to the surveillance requirements for the reactor safety and measuring instrumentation.

\section{Objective:}

The objective is to ensure that the reactor safety systems will be in an operable condition if needed to provide for any required safety action and that the measuring instrumentation is reliable.

\section{Spectifications:}

a. Testing of the safety system shall be required:*

(1) Prinr tin each startup following refuelilug (except for the "chamber add" and "FFED" tests which cannot be made until the reactor is at power).

(2) Immediately after any change or maintenance involving any component of the safety system.

(3) During operation, at least weekly.

b. Each safety channe1* (as 1isted in Table 3.2, page 3-9) shall be calibrated at least annually.

c. The main pump cutoff channels will be tested semiannually.

d. Measuring channels:

(1) The count rate channclo shall be under continuous electronic surveillance during operating modes where operability of these channels is required (see Section 3.4). These channels shall be calibrated annually.

(2) Continuous surveillance of the servo channels is maintained by interlocks which require that all three servo channels be operable in order to obtain "start" in Mode 1 operation. These channels shall be callbrated annully.

(3) A channel check of the reactor bay containment flow monitor shall be made at least once per shift during reactor operation.

*Except for the main pump cutoff channel which is tested semiannually. 
(4) A channel check of the closed off-gas system vacuum monitor shall be made at least once per shift during reactor operation in Mode 1.

(5) A channel check of the instrument air system pressure monitor shall be made daily during reactor operation.

e. Any channel intentionally placed in the tripped condition will be checked at least once each shift to verify that it is in the tripped condition.

Bases:

Built-in test capabilities combined with the two-out-of-three channels coincidence design enable frequent channel tests and maintenance of the reactor safety system while the reactor is operating. Detailed bases for the weekly test interval in the above specification is given in Reference 14. These operational and post-maintenance tests coupled with the required prestartup tests ensure that the reactor safety system remains in an operable condition. An annual calibration frequency has proven to be sufficient to ensure a high degree of reliability.

A11 reactor measuring instrumentation channels are at least duplicated and in most cases triplicated. The availability of similar, but independent, Instruments monitoring the same variable makes intercomparison an effective method of ensuring reliability. Continuous electronic monitoring of the count rate channels has been effective in detecting the most common types of failures experienced. The annual calibration frequency specified for the count rate and servo channels has proved to be sufficient to ensure a high degree of reliability. Channel checks at the specified frequency applicable to the remaining three measuring channels has proven sufficient to ensure a high degree of reliability. 


$$
4-6
$$

\subsection{SBHE Filter Efficiency}

Applicability:

This specification applies to the survelllance requirements for SBHE filter efficiency.

Objective:

The objective is to ensure compliance with the requirements of Section 3.5 .

\section{Specifications:}

The efficiency of the SBHE filters shall be measured at least semiannually and after any filter replacement before use of the replaced filters in the SBHE system.

Bases:

Operating experience has demonstrated that measurement of the filter efficiencies at the frequency specified above provides adequate assurance that the requirements of Section 3.5 are satisifed. 


\subsection{Containment}

\section{Applicability:}

This speciflcation applies to the surveillance requirements of the containment systems.

\section{Objective:}

The objective is to ensure the operability of the containment systems. Specifications:

a. Operation of the automatic block valves in the primary system pressure letdown lines shall be given a functional test at least annually.

b. Reactor bay in-leakage shall be measured at least annually.

c. Checks shall be made at least daily to ensure that at least one SBHE fan is in operation and one is in standby. Low flow alarms indicate any failures of the operating fan.

d. Checks shall be made at least daily to ensure that one start-ondemand diesel-generator is available for use.

Bases:

Three major barriers guard against the release of radioactivity from the HFIR. The fuel cladding is the first line of defense. Should it be breached, the radioactivity is contained by the primary high pressure system. Finally, if it is released to the atmosphere inside the reactor building, the SBHE filter system should trap it.

Safety limits sperified in Section 2 protect the fuel element cladding. If a release of activity to the primary system should occur, the automatic block valves should close and prevent further dispersion. An annual functional test of these valves is considered adequate to ensure their proper operation when required. Measurements and checks at the specified frequencies have proven to be sufficient to ensure a high degree of reliability, 


\subsection{Primary Coolant System}

\section{Applicability:}

This specification applies to the surveillance requirements for operation of the primary coolant system for Mode 1 operation.

Objective:

The objective is to ensure compliance with the specifications set forth in Section 3.7.

\section{Specifications:}

a. Pressure safety valves shall be tested annually.

b. Bulk outlet water temperature shall be under continuous surveil-

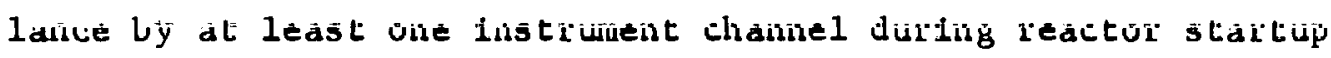
and operation.

c. Bulk inlet water temperature shall be under continuous electronic surveillance by at least one instrument channel during reactor startup and operation.

d. Operability of the pressurizer pump high pressure cutoff will be checked on an annual basts.

\section{Bases:}

Surveillance at the above specified frequencies ensures compliance with the specifications set forth in Section 3.7. Electronic and pneumatic instrumentation monitors the various parameters to assure compliance. Primary pump performance curves indicate a maximum of $365 \mathrm{ft}$ THD at $5,000 \mathrm{gpm}$. With a total of three pumps in service, the maximum allowable differential pressure across the vessel cannot be exceeded.

Primary system pressure is maintained below the maximum allowable operating pressure of 1,000 psig by a pressure relief valve, but, in addition, there are other lines of defense. The normal operating pressure is $750 \mathrm{psig.} \mathrm{It} \mathrm{is} \mathrm{maintained} \mathrm{at} \mathrm{this} \mathrm{level} \mathrm{by} \mathrm{an} \mathrm{automatic} \mathrm{pressure}$ controller. If the system pressure should rise, an annunciator alerts the operator at 800 psig. Finally, at $\leq 900$ psig the pressurizer pumps are de-energized. 


\subsection{Limitations on Experiments}

Applicability:

This specification applies to the surveillance requirements for experiment limitations.

Objective:

The objective is to assure compliance with the specifications set forth in Section 3.8 regarding limitations on experiments.

\section{Specifications:}

a. The Technical Department of the Operations Division shall review and examine all experiments proposed for insertion into the reactor for safety, potential hazards, and compatibility with the operation of the reactor and other experiments.

b. New or unusual experiments shall be submitted with recommendations of the Technical Department to the Reactor Experiment Review Committee (RERC) for review in accordance with the provisions of Section 6.11 of these technical specifications.

c. Tried experiments may be approved by the Technical Department without further review by the RERC.

\section{Bases:}

Review of experiments in accordance with the above specifications adequately assures compliance with the specifications set forth in Section 3.8 . 


\subsection{Emergency Core Cooling}

\section{Applicability:}

This specification applies to the surveillance requirements applicable to the emergency core cooling system.

Objective:

The objective is to ensure the reliability of the emergency core cooling system.

\section{Speciftcations:}

Each pony motor battery bank shall be checked at least semiannually by load testing and monitoring the battery voltage as a function of time. Bases:

The capacity of alkaline-type batteries, such as the pony motor battery banks, can only be measured by a load test. Since any one pony motor pump can supply the post-shutdown coolant requirements and at least two pony motors must be in service for reactor operation in Mode 1 (Section 3.9), load testing of each of the four pony motor battery banks on a semiannual frequency is considered adequate to ensure rellable postshutdown emergency coolant. 


\subsection{Emergency Shutdown System}

\section{Applicability:}

This specification applies to the survelllance requirements of the emergency shutdown system.

Objective:

The objective is to ensure the operability of the emergency shutdown system.

Specifications:

a. A functional test of all valves and controls in the emergency shutdown system will be performed at least annually.

b. The specific gravity, temperature and tank level of the cadmium nitrate solution will be checked at least monthly to determine the poison amount available for emergency shutdown.

Bases:

Operation of the emergency shutdown system depends upon the performance of remotely controlled valves which are not routinely in use. Since they are not subjected to routine operating stresses, their failure rate due to wear is very low. However, their operability from the standby status must be checked sufficiently often to ensure that they will function properly when needed. The specified functional test frequency and cadmium solution concentration and solution volume checks are considered sufficient to ensure a high degree of reliability. 


\subsection{Water Height $\Lambda$ bove Core}

\section{Applicability:}

These specifications apply to the surveillance requirements for height of water above the core centerline in the various modes of reactor operation.

\section{Objective:}

The objective is to ensure compliance with the specifications set forth in Sertinn 3.11 .

\section{Specifications:}

a. Surveillance of the pool water level shall be made at each reactor startup using the startup check list.

b. Surveillance of the pool water level shall be made daily during reactor operation.

\section{Bases:}

Pool system design dictates that a positive action is required to drain the pools. This coupled with routine water level checks ensures the minimum water height above the core will be malntained during each of the operating modes. 
4.12 Installation of Target or Its Equivalent in the Flux Trap

Applicability:

This specification applies to the surveillance requirements for installation of the target or its equivalent in the flux trap.

Objective:

The objective is to assure compliance with the specification set forth in Section 3.12.

Specifications:

A visual core inspection to verify the installation of the target or its equivalent shall be made prior to each startup subsequent to a shutdown in which the vessel is opened.

Bases:

Surveillance at the frequency specified above is adequate to ensure that the reactor is never operated without the target or its equivalent in the flux trap. 


\subsection{Radiation Monitoring Equipment}

\section{Applicability:}

This specification applies to the surveillance requirements for the personnel protection radiation monitoring equipment.

Objective:

The objective is to ensure that the radiation monitoring equipment is operable.

\section{Specitications:}

A test of the radiation monitoring equipment for operability shall be conducted at least semiannually.

\section{Bases:}

Experience has indicated that area radiation monitors operate quite reliably for long periods of time. Nevertheless, their fallure at any point in time cannot be discounted or predicted. Therefore, all the radiation monitors in the plant-wide radiation detector system are continously monitored electronically to detect the most common types of failures expected. These devices are primarily used to detect moderate increases in the ambient radiation levels. Their alarm point is set at a small value above background and absolute accuracy is not essential. Hence, the semiannual test for operability combined with the continual electronic monitoring is considered adequate to ensure that the equipment remains in proper operation. 


\subsection{Core Components}

Applicability:

This specification applies to the surveillance requirements of the reactor components.

Objective:

The objective is to inspect reactor components frequently enough to detect unsafe mechanical wear or radiation damage before these conditions can adversely affect reactor operations.

Specifications:

Reactor components and reactor vessel top head studs shall be inspected for physical deformation, mechanical wear, or radiation damage at least annually.

Bases:

Frequent inspections during the ten years the reactor has been operating have verified the adequacy of the design. Combined with external tests such as safety rod time-of-flight, the specified inspection frequency is more than adequate to detect inciplent damage to reactor components. 


\subsection{Emergency Power}

\section{Applicability:}

This specification applies to the surveillance of the emergency power sources required for reactor operation.

\section{Objective:}

The objective is to ensure that emergency power is always available to maintain the reactor in a safe shutdown condition and to provide reactor hay rontainment.

\section{Spenificationr:}

a. Each of the two standby diesel-generators shall be started and operated for a minimum of 30 minuteo under $30 \%$ of nominal full load at least monthly. A check list of diesel test performance shall be recorded and filed.

b. Should one of the two standby diesel-generators become inoperable, the operable diesel-generator shall be tested as specified above at least weekly. A check list of diesel test performance shall be recorded and filed.

c. The normal-emergency system test, which provides a load test on the diesel-generators, shall be performed at least annually.

d. The switchgear battery bank shall be load tested annually.

\section{Bases:}

The HFIR is equipped with two diesel-generators, each capable of supplying the full reactor emergency load. Specified test frequencies are consistent with industry practice and are considered adequate to ensure a reliable source of emergency power.

The capacity of alkaline-type batteries, such as the switchgear banks, can only be measured by a load test. The specified load test frequency is consistent with industry practice and is considered adequate to ensure a reliable source of switchgear power. 


\section{DESIGN · FEATURES}

\subsection{Reactor Fue1}

Applicability:

This specification applies to the fuel elements used in the reactor core.

Objective:

The objective is to ensure that the fuel elements are of such design and fabricated in such a manner as to permit their use with a high degree of reliability with respect to their physical and nuclear characteristics.

\section{Specifications:}

The fuel assembly for. the reactor consists of two concentric fuel elements containing vertically oriented curved plates. The elements are designated as the inner element and the outer element. The inner element, which has 171 fuel plates, contains $22.8 \mathrm{~g}$ of ${ }^{10} \mathrm{~B}$ burnable poison. The outer element has 369 fuel plates but no burnable poison. Material requirements for the fuel plates are as follows:

a. Fuel plates: $\mathrm{U}_{3} \mathrm{O}_{8}-\mathrm{Al}$ cermet, $\mathrm{Al}$ cladding

b. Type aluminum powder: ALCOA 101 or equal

c. Type alumfnum cladding, side end plates: ALCOA 6061 or equal

d. Enrichment of $\mathrm{U}-235$ in $\mathrm{U}_{3} \mathrm{O}_{8}$ : $\sim 93 \%$

e. Weight of U-235 per plate in inner fuel element in grams: $15.18 \pm 1 \%$

f. Weight of U-235 per plate in outer fuel element in grams: $18.44 \pm 1 \%$

g. Total fuel loading of U-235 in $\mathrm{kg}$ : $9.40 \pm 1 \%$

h. Weight of boron-10 (as $B_{4} C$ ) per plate in inner fuel element in grams: $0.0164 \pm 10 \%$

1. Total burnable poison loadings (boron-10 in inner fuel plates only) in grams: $2.8 \pm 10 \%$

\section{Bases:}

Calculations and experiments during the design and experience during operation of the reactor indicate this type of fuel element meets the criteria for reliability and performance. 


\subsection{Reactor Bay}

\section{Applicability:}

This spectfication applies to the room which houses the reactor.

\section{Objective:}

The objective is to ensure that provisions are made to restrict the amount of airborne radioactivity released to the environment.

\section{Specifications:}

The reactor shall be housed in a room designed to be maintained at negative pressure with respect to adjacent rooms and the outside.

\section{Bases:}

The ventilation system is designed to exhaust air from the reactor bay at a rate to ensure leakage into the reactor bay and to maintain a slight negative pressure within the reactor bay with respect to outside ambient pressure. The air exhausted from the reactor bay passes through a series of filters before being discharged through a stack to the atmosphere. The ventilation system is in continuous operation during all modes of reactor operation and during in-pool movement of irradiated fuel. 


\subsection{Fuel Storage}

Applicability:

This spectfication applies to storage facilities for new and irradiated fuel.

Objective:

The objective is to store fuel in such a manner as to ensure subcritical conditions and ensure adequate cooling and shielding for irradiated fuel.

\section{Specifications:}

a. All fuel elements shall be stored in a geometrical array ensuring subcriticality for all conditions of moderation.

b. Irradiated fuel shall be stored in a manner which will provide natural convection cooling and adequate shielding.

c. Freshly irradiated fuel elements shall be stored in specially shielded, storage racks in the pool for the first 24 hours after shutdown to protect the pool wall concrete from overheating.

\section{Bases:}

Unirradiated fuel elements are stored in specially designed fuel storage containers which énsure subcriticality, even under flooded conditions, by physically limiting the storage of elements to a specific array.

Irradiated fuel storage racks are located in the storage pools at a depth sufficient to provide adequate water shielding above the fuel elements. The storage racks are designed to provide natural convection cooling for the fuel elements. Natural convection cooling is adequate to maintain the integrity of the fuel cladding. 


\section{ADMINISTRATIVE CONTROLS}

\subsection{Organization}

The Oak Ridge National Laboratory, which is owned by the United States Energy Research and Development Administration and operated under contract by the Nuclear Division of Union Carbide Corporation, shall be responsible for operation and supervision of the facility. The Operations Division shall be directly responsible for the operation of the facility. The reactor's relationship to the Laboratory's structure is shown in Figure 6.1 . 


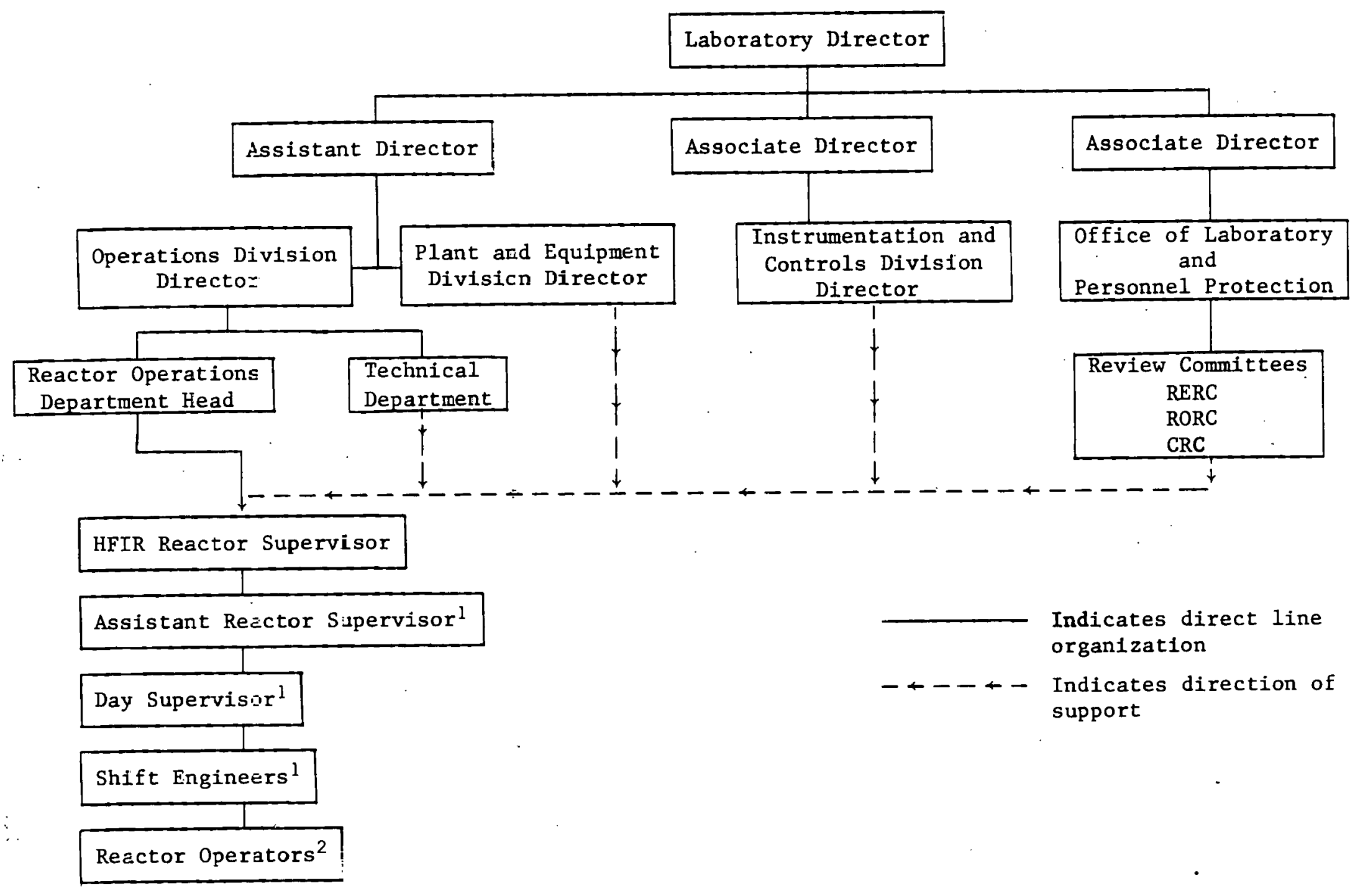

Shall be certified senior reactor operator.

${ }^{2}$ Shall be certified reactor operator.

FIGURE 6.1. ORGANIZATIONAL CHART 


\subsection{Personnel Qualffication}

a. The reactor shall be operated by personnel examined and certified under the general provisions of ERDA Manual Chapter 0540 and approved by the - Operations Division Director.

b. Jobs requiring an operator's or a senior operator's certification are indicated in Figure 6.1, Organizational Chart. 


\subsection{Staff Requirements}

a. The minimum personnel on duty during reactor operation shall be:

(1) One certified senior operator; and

(2) One certified operator.

b. The control room shall be attended by at least one certified operator at all times during reactor operation.

c. At least one certified sentor operator shall be present in the control room during reactor startup. 


\subsection{Facility Modifications}

a. Changes in technical specifications or modifications to the plant protection, reactivity control systems, or engineered safety features, or changes that involve a safety question not reviewed in the safety analysis report shall require prior review and authorization by the RORC and ERDA.

b. Certaln mechanical and instrumentation and control design changes may be made by the contractor provided the effect of the change does not involve a change in a technical specification or an unreviewed safety question. Formal procedures shall be established for documenting Important mechanical and instrumentation and control design changes. 


\subsection{Operating Procedures}

a. The reactor shall be operated in accordance with documented operating procedures. In no instance will the operating procedures designate authorization to operate the reactor outside the bounds of any specification listed in this document. The procedures shall be adequate to ensure safe operation of the reactor but should not preclude the use of independent judgment and action should the situation require 1 . Detailed written procedures shall be provided for, but not limited to, the following:

(1) Emergency and abnormal conditions including evacuations.

(2) Reactor startup, operation, and shutdown.

(3) Installation and removal of fuel elements, control rods, and all non-permanent reactor components.

(4) Routine maintenance of control rod drives and reactor safety systems .

b. A standard method shall be used to change operating procedures as necessary to ensure that all persons concerned are notified of the change and that a permanent record is made. Permanent procedure changes must be formally written and approved by at least two of the following senior staff members:

(1) Operacions Division Director

(2) Reactor Operations Department Head

(3) HFIR Supervisor

(4) Assistant Reactor Supervisor

(5) Day Supervisor

Temporary changes to the procedures that do not alter the original procedure intent shall be made, when required, by issuing special operating instructions. Special operating instructions shall he. approved by at least two of the senior staff members listed above.

c. Radiation protection procedures shall be maintained and made available to all Operations personnel. 


\subsection{Action to Be Taken in the Event \\ A Safety Limit Is Exceeded}

In the event a safety limit is exceeded:

a. The reactor shall be shut down and reactor operation shall not be resumed unt 11 authorized by ERDA.

b. An immediate report shall be made to the Director of Laboratory and Personnel Protection.

c. A report shall be made no later than the next work day to ERDA.

d. A report shall be made which shall include an analysis of the causes and the extent of possible resultant damage, effectiveness of corrective action, and recommendations for measures to prevent or reduce the probability of recurrence. This report shall be sent to the Reactor Operations Review Committee (RORC) and a similar report submitted to ERDA when authorization to resume operation of the reactor is sought. 


\subsection{Action to Be Taken in the Event of An Abnorinal Occurrence}

In the event of an abnormal occurrence, as defined in Section 1 , the following action shall be taken:

a. The reactor supervisor and other appropriate management personnel shall be notified and corrective action taken.

b. A report shall be made which shall include an analysis of the cause of the occurrence, efficacy of corrective action and recommendations for measures to prevent or reduce the probability of recurrence, in accordance with ERDA Manual Chapter 0502.

c. When required, a report shall be submitted to ERDA. 


\subsection{Reporting Requirements}

a. A notification shall be made no later than the next work day to the Safety Division, USERDA, Oak Ridge Operations of the following conditions:

(1) Any release of radioactivity to the environment above the permissible limits specified in ERDA Manual Chapter 0524.

(2) Any violation of a safety limit (Section 2.1).

(3) Any exposures to personnel in controlled or uncontrolled areas that exceed the standards in ERDA Manual Chapter 0524.

b. A report shall be made within three work days to ERDA-ORO of any violation of the technical specifications. 


\subsection{Actions to Be Taken in Regard to Potential Degradations of A Reactor Shutdown System}

a. Immediate remedial actions required:

(1) Upon experiencing a Class 1 degradation of the reactor shutdown system, the reactor shall be shut down immediately by manual scram or other emergency backup means that may be necessary.

(2) Upon the discovery of a Class 2 degradation of the reactor shutdown system, the reactor shall be shut down immedlately in an orderly (non-emergency) manner, except when the situation warrants more urgent shutdown action be taken.

(3) Upon the discovery of a Class 3 degradation of the reactor shutdown system, the contractor shall take the applicable course of action below:

(a) For coincident logic systems, the degraded unit shall be promptly placed (or kept) in the tripped state until operabillty is restored, except for the brief time necessary to determine the operability of the redundant channels. If the action above would result in an automatic scram, this requirement should be satisfied instead by the prompt initiation of an orderly shutdown.

(b) For one-out-of-two or -three systems, where a bypass of a channel for shurt time periods is authorized in order to permit testing or repair, the bypassed condition may be retained. If operability cannot be regained by the end of the pertod authorized for bypass, the reactor shall be immediately shut down in an orderly manner, except when the situation warrants more urgent shutdown action be taken.

(4) Upon the discovery of a class 4 degradation of the reactor shutdown system, the sontractor shall ascertain the root cause of the degradation and implement appropriate corrective action designed to correct the spectfic degradation and to reduce the probability of similar occurrences. 
b. Required notification to ERDA:

(1) In the event of a Class 1 degradation, the contractor shall verbally notify ERDA immediately and provide a written report within five calendar days.

(2) In the event of a Class 2 degradation, the contractor shall verbally notify ERDA as expeditiously as practical but within 24 hours and provide a written report within five calendar days.

(3) In the event of a Class 3 degradation, the contractor shall provide a written report to ERDA within five calendar days.

(4) In the event of a Class 4 degradation, the contractor shall include the occurrence in a written report to ERDA provided no later than the end of the month following the occurrence.

c. Authorization for re-startup of the reactor:

Following the occurrence of either a Class 1 or Class 2 degradation of the reactor shutdown system, authorization from ERDA is required for restart. 


\subsection{Operating Records}

In addition to the requirements of applicable regulations, and in no way substituting therefore, records and logs shall be prepared for at least the following items and retained for a period of at least five years:

a. Normal plant operation

b. Principal maintenance activities

c. Abnormal occurrences

d. Equipment and component surveillance activities required by the technical specifications

P. Fuel inventories and cransfers

f. Experiments performed with the reactor

g. Updated, corrected, and as-built drawings of the facility (these shall be retained for the lifetime of the facility). 


\subsection{Review Committees}

\subsubsection{Reactor Operations Review Cómmittee}

There shall be a Reactor Operations Review Committee (RORC) responsible for periodically conducting an independent safety review of the reactor facility. The members of the RORC shall be appointed by the Director of the Laboratory and shall not be directly involved in the operation of the reactor. The committee members shall collectively possess expertise in all areas of reactor operations and safety.

The RORC shall meet with the operating personnel as frequently as it deems necessary to keep informed of any operational problems or potential hazards. The committee shall conduct at least one formal review annualiy and the minutes of this review shall be reported in writing to the Director of the Laboratory. In compliance with the requirements of IAD $8401-7$, the RORC shall review any proposed modifications which have safety significance. A detailed description of the committee's function and method of review is presented in Reference 18. 


\subsubsection{Reactor Experiment Review Committee}

There shall be a Reactor Experiment Review Comnittee (RERC) responsible for reviewing any new or unusual experiments proposed for insertion into the reactor. The RERC shall review proposed experiments in such detall as to ensure that no credible failure or malfunction of the experiment could create a positive change in reactivity greater than the reactor safety system was designed to accommodate. The committee shall review experiments from the standpoint of personnel and equipment safety and the continuity of reactor operations. The committee shall, as it deems necessary, place limits upon any material, systems, components, effluents, or operations that may present a hazard to personnel or to the reactor. I'he Committee shall in executing its responsibility make recommendations or establish conditions on design, construction, and operation of an experiment. A detailed description of the committee's functions and method of review is presented in Reference 18. 


\subsubsection{Criticality Committee}

There shall be a Criticality Committee responsible for the review and approval of operations which involve handling, storage, transportation, and disposal of significant quantities of fissile material. The committee shall on request serve as a consulting group and provide assistance in problems involving criticality. The committee shall conduct an annual review of all areas contalning significant amounts of fissile material to ensure that approved procedures are being followed. A detailed description of the committee's functions and method of review is presented in Reference 18. 


\subsection{Monitoring of Airborne Effluents}

Normally four different radiation monitors, operable during reactor operation, provide the operator with information related to potential or actual release of radioactive effluents from the HFIR stack. These are:

a. The cladding failure monitor;*

b. A primary coolant water $\beta-\gamma$ activity monitor;*

c. A primary coolant deaerator off-gas $\beta-\gamma$ monitor; and

d. A HFIR duct particulate $\beta-\gamma$ monitor.

Any, one of these is sufficient to provide the operator with information related to potential or actual release of radludillve efflueuls fiuiu the HFIR stack. An alarm is actuated in each of these four instrument channels by radiation levels exceeding a level no greater than ten times "current normal" levels. In the event an alarm is received on any of these channels an immediate investigation will be initiated by Reactor Operations supervision to ascertain the cause and to determine the appropriate necessary remedial action. In addition, the output signals from each of these raunitoring channels is continuously recorded. The signal from the HFIR duct particulate $\beta-\gamma$ monitor as well as signals from other radiation monitors on the HFIR stack is telemetered to a Laboratory Central Waste Monitoring Station which is continuously manned by personnel of the Laboratory Process Waste Disposal Group. Procedures of this group require an investigation into the cause of radiation levels exceeding about $120 \%$ of normal levels.

*Primary coolant flow past these detectors is automatically shut off upon primary coolant system isolation initiated by the FFED. 


\subsection{Control Rod Replacement with New Control Rods}

Simultaneous replacement of both the set of four shim-safety plates and the regulating cylinder with new (unused) rods is administratively prohibited. If operating requirements dictate the necessity for replacement of both sets with new (unusued) rods for a particular fuel cycle, one or the other will first be replaced; a critical run will be made to verify that the poison content of the replaced rod is effectively nominal, and then the other will be replaced. 


\section{REFERENCES}

1. H. A. McLain, HFIR Fuel Element Steady-State Heat Transfer Analysis Revised Version, ORNL-TM-1904 (December, 1967).

2. Letter from W. R. Gambill to J. A. Cox, "Minimum Steady-State Thermal Burnout of the HFIR" (January 22, 1974).

3. W. R. Gambill, Design Curves for Burnout Heat Flux in Forced-Convection Subcooled Light-Water Systems, ORNL-TM-2421 (November 14, 1968).

4. T. M. Sims and J. H. Swanks, Heat Transfer Calculations for HFIR Technical Specifications - Bases for Safety Limits and Limiting Safety System Settings [to be published (anticipated publication date - July, 1977)]

5. F. T. Binford, et al., The High Flux Isotope Reactor Accident Analysis, ORNL-3573 (Apri1, 1967).

6. R. D. Cheverton, O. W. Burke, and T. E. Cole, HFIR Transients and Reactivity Accountability, ORNL-TM-1747 (January 18, 1967).

7. Reactor Instrument and Controls Design Change Memo No. HFIR-88 (October 25, 1976).

8. Letter from 0. W. Burke to L. C. Oakes, "Analog Computer Analysis of Loss of Pressure Accidents in HFIR" (January 15, 1963).

9. R. D. Cheverton and T. M. Sims, HFIR Core Nuclear Design, ORNL-4621 (July, 1971).

10. Internal Correspondence from R. D. Cheverton and T. M. Sims to Distribution, "Analysis of Selected HFIR Critical Experiment Data for Period August 25 through October 22, 1965" (December 1, 1965).

11. Letter from S. J. Ditlo to R. V. McCord, "HHLK Scram Delay Tests" (December 4, 1975).

12. Letter from K. W. West to S. J. Ditto, "HFIR Magnet Release Tíme" (May 9, 1975).

13. Letter from T. E. Cole to S. J. Ditto, "HFIR - Poison Injection System" (August 24, 1966).

14. Letter from E. F. Epler to J. A. Cox, "Test Frequency of the HFIR Protection System" (October 3, 1967).

15. F. C. Maienschein, et al., Attenuation by Water of Radiation from A Swimming Pool-Type Reactor, ORNL-1891 (September 7, 1955). 
16. F. T. Binford, T. E. Cole, and E. N. Cramer, The High Flux Isotope Reactor - A Functional Descr1ption, ORNL-3572 (Rev. 2) (May, 1968).

17. Letter from R. S. Stone to K. W. West, "HFIR Safety Dynamics in Modes 2 and 3" (October 25, 1976).

18. Internal Correspondence from D. M. Davis to Distribution, "The Safety Program of Oak Ridge National Laboratory" (May 7, 1975). 
APPENDIX

\section{ACCIDENTS AND ANTICIPATED TRANSIENTS}

Various accidents and anticipated transients were analyzed for the HFIR and their consequences are summarized in the accident analysis report and other documents.

Four general types of reactivity accidents, categorized according to their mechanisms for occurrence, were considered. They are as follows:

1. Reactivity additions associated with the control elements (Reference 5, pages 75-80) (anticipated transients and accidents).

2. Reactivity additions associated with "voids" in the central target region (Reference 5, pages 78 and 80-82) (accidents).

3. Reactivity additions associated with cold water insertion (Reference 5, pages 82-83) (anticipated transients).

4. Reactivity additions associated with the target in the island (Reference 5, page 82) (accidents).

With regard to Mechanism No. 1 (control plate accident), it was concluded from the analyses that reactivity additions from runaway control elements would result in no serious cure damage and, in particular, no melting of the hot spots (Reference 5, page 80 ).

The shim drive speed is $5.75 \mathrm{in.} / \mathrm{min}(0.096 \mathrm{in.} / \mathrm{sec})$, and the regulating drive speed is $15 \mathrm{in.} / \mathrm{min}(0.25 \mathrm{in.} / \mathrm{sec})$. With the control elements initially at the clean core symmetrical critical position, the differential worth of the shim-regulating cylinder is $1.19 \% \Delta \mathrm{k} / \mathrm{k} / \mathrm{in}$. and that of the set of four shim-safety plates is $1.03 \% \Delta \mathrm{k} / \mathrm{k} / \mathrm{in}$. For this initial control element position and for the maximum drive speed condition with all five control elements being withdrawn, the reactivity addition rate would be $0.0051 \mathrm{\Delta k} / \mathrm{k} / \mathrm{sec}$ for the first inch of travel and $0.0021 \mathrm{\Delta k} / \mathrm{k} / \mathrm{sec}$ for about the next 2 in., after which it decreases. An accident in which the control elements can add reactivity is associated with the structural integrity of the shim-regulating cylinder drive mechanism. The use of a control element that must be inserted against gravitational and hydraulic forces introduces a possible problem in connection with failure of the supporting or drive mechanism; such a failure would result in withdrawal of the control element and thus in a positive reactivity addition. In the event of a 
mechanical failure of the drive mechanism, a hydraulic cylinder on the lower end of the drive rod will act as a shock absorber (normally used to balance the downward forces of gravity and pressure on the shim-regulating cylinder drive mechanism) and will limit the shim-regulating cylinder maximum withdrawal speed to $39 \mathrm{in.} / \mathrm{min}(0.65 \mathrm{in} / \mathrm{sec})$, even if the force balancing feature is depressurized. The corresponding maximum reactivity addition rate would be about $0.0078 \Delta \mathrm{k} / \mathrm{k} / \mathrm{sec}$.

The results from analog calculations made in connection with the control element reactivity accidents indicate that for beginning of cycle Mode 1 operation at full flow ( $42 \mathrm{fps}$ ) and full power (100 MV) and with the safety plates in the least sensitive position (normally they would not be in this position) $0.050 \mathrm{\Delta k} / \mathrm{k} / \mathrm{sec}$ can be inserted continuously without the hot spot heat flux exceeding the burnout heat flux (Reference 5, pages 79-80 and page 78, Iable 1.c.4, Part 1, Casc No. 16). For this case the system pressure was 600 psi (Reference 6, page 12) and the inlet coolant temperature was $120^{\circ} \mathrm{F}$ (Reference 6 , page 14). Scram was initiated by a rate trip signal at $20 \mathrm{MW} / \mathrm{sec}$ (Reference 5, page 78, Table 1.c.4, Part 1, Case 16).

Starting from very low power $\left(5 \times 10^{-8} \mathrm{MW}\right)$ and full flow (42 fps) in Mode 1 the self shutdown mechanism dlute limited the paak heat f1ux to less than the burnout heat flux when reactivity was added at the rate of $0.005 \Delta \mathrm{k} / \mathrm{k} / \mathrm{sec}$ (Reference 5, page 80 aud page 78, Table 1.c.4, Part 1 , Case No. 17). For this case lhe syscem pruivure was 600 pri (Reference 6 , page 12) and the inlet coolant temperature was $120^{\circ} \mathrm{F}$ (Reference 6 , page 14).

In regard to transients in Modes 2 and 3, the safety system has been modifier from that considered in the accident analysis report (Reference 5). This modification is described in detail in Reference 7 . The change directly affects the safety system by: (1) disabling the rate trip for Modes 2 and 3 operation; and (2) the installation of signal suvothing capacitors in the safety flux signal conditioner modules. The rate trip was originally included for Modes 2 and 3 operation not because it was required but because additional circults would be necessary to disable the trip and no operational difficulties were anticipated by letting the trip remain active. 
The analysis of Reference 17 (pages 1 and 2) of the Mode 3 startup accident with no rate trip and with the smoothing capacitor installed indicates no significant core temperature rise.

The results of analysis reported in Reference 5 (page 78, Table 1.c.4, Case 24) for normal Mode 2 flow rates indicate no safety action is required to prevent hot spot melting for the Mode 2 optimum void accident occurring at the start of the fuel cycle. The analysis of Reference 17 (pages 2 and 3) indicates that with safety action and with the proposed changes to the safety system this type of accident, whether it occurs at the beginning of the fuel cycle or at the end (Reference 17, page 3), results in inconsequential peak hot spot temperatures.

For the abnormal situation of Mode 2 or 3 operation with full pressure and full flow, analysis reported in Reference 17 (pages 3 and 4) indicates that the optimum void accident could result in melting at the hot spot. However, the Modes 2 and 3 cases with smoothed signals and no rate trip have less heating in the hot spot than does the normal Mode 1 case with rate trip and undelayed signals.

With regard to Mechanism No. 2 (voids in the central target region), there are several ways in which voids might possibly be added to the flux trap during normal operation with the target in place. These include:

1. The formation of a vortex, in which case the void could be maintained in the island for a significant period of time;

2. The sweeping in of bubbles with the coolant flow, in which case the void could be maintained only if enough bubbles were available; and

3. The blockage of flow to the target and subsequent steam formation in the flux trap.

Cases 1 and 2 appear to be the most serious because the voids can enter more rapidly.

The analyses indicate that hot spot burnout occurs to the Mode 1 "optimum" void accident and for an $0.8 \% \Delta \mathrm{k} / \mathrm{k}, 30 \mathrm{msec}$ ramp addition at the end of the fuel cycle (Reference 5, page 78, Table 1.c.4, Part 1, Case Nos. $1,8,9,10,11$, and 14). However, no breach of the primary containment system integrity results from this accident. The HFIR is designed to safely and adequately contain, shield, and clean up the fission product 
releases resulting from this accident. The results of calculations of the effects of reactivity additions associated with various void insertions are summarized in Reference 5 (page 78, Table 1.c.4, Part 1). Various initial conditions as to flow and reactor power were used, and the specific values used for each case are given in the c1ted table. The system pressure was 600 psi (Reference 6, page 12) and the inlet coolant temperature was $120^{\circ} \mathrm{F}$ (Reference 6 , page 14 ). In most cases considered a rate or level trip initiated scram as specified in the cited reference.

With regard to Mechanism No. 3 (cold water insertion), the analyses indicate that no hot spot burnout would result from these anticipated transients (Reference 5, pages 82-83).

With regard to Mechanism No. 4 (the target), the analyses indicate that no hot spot burnout would result from these accidents (Reference 5, page 82 ).

The effects on the HFIR system of loss of primary system pressure (initially at $600 \mathrm{psi}$ ) through various leak sizes ranging from $5 / 8$ in. diameter to $3 \mathrm{in}$. diameter were investigated using the analog computer. The results are documented in Reference 8 . The results show that for the largest leak size analyzed, no. burnout occurs provided the reactor is scrammed at 200 psi or above and provided the electrical power to the main circulating pumps is cut off at 300 psi or above.

An analysis of the accident in which it is assumed that with the reactor operating at $100 \mathrm{MW}$ a step decrease in pressure occurs in which the pressure is instantly decreased from 40 atm to 1 atm 1 given in the accident analysis report (Reference 5, pages 132-134). The reported results indicate no hot spot burnout. It is further stated that the design of the facility is adequate to reduce the probability of such a failure to such a low level that it is not expected to occur during the life of the facility. 
1. R. G. Affel

2. J. L. Anderson

3. D. S. Asquith

4. K. S. Belitz

5. F. T. Binford

6. F. R. Bruce

7-8. G. H. Burger

9. 0. W. Burke

10. C. D. Cagle

11. W. R. Casto

12. R. D. Cheverton

13. T. E. Cole

14. J. A. Conlin

15-16. B. L. Corbett

17-66. J. A. Cox

67. W. H. Culbert

68. F. L. Culler

69. S. J. Ditto

70. E. D. Gupton

71. T. P. Hamrick

72. C. H. Helton

73. L. B. Holland

74. S. S. Hurt, III

75. J. D. Jenkins

76. E. B. Johnson

77. F. B. K. Kam

78. H. V. Klaus

79-88. R. V. McCord

89. H. A. McLain

90. J. R. McWherter

91. .T. M. Miller.

92. L. C. Oakes

93. H. Postma

94. K. H. Poteet

95. M. E. Ramsey

96. W. H. Sides

97. T. M. Sims

98. M. J. Skinner

99. R. S. Stone

100. J. H. Swanks

101. K. W. West

102. M. K. Wilkinson

103. A. Zucker

104-105. Central Research Library

106. Ducunint Reference Section

107. Nuclear Safety Information Center

108-109. Laboratory Records Department

110. Laboratory Records, ORNL R.C.

111-115. Research and Technical Support Division, ORO

116-142. Technical Information Center, Oak Ridge 